\title{
Olig2 SUMOylation protects against genotoxic damage response by antagonizing p53 gene targeting
}

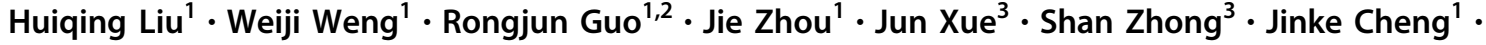 \\ Michael X. Zhu $\mathbb{1}^{4} \cdot$ Si-Jian $\mathrm{Pan}^{3} \cdot$ Yong $\mathrm{Li}^{1}$
}

Received: 28 September 2019 / Revised: 19 May 2020 / Accepted: 20 May 2020 / Published online: 1 June 2020

(c) The Author(s), under exclusive licence to ADMC Associazione Differenziamento e Morte Cellulare 2020. This article is published with open access

\begin{abstract}
Posttranslational modifications of nuclear proteins, including transcription factors, nuclear receptors, and their coregulators, have attracted much attention in cancer research. Although phosphorylation of oligodendrocyte transcription factor 2 (Olig2) may contribute to the notorious resistance of gliomas to radiation and genotoxic drugs, the precise mechanisms remain elusive. We show here that in addition to phosphorylation, Olig2 is also conjugated by small ubiquitin-like modifier-1 (SUMO1) at three lysine residues K27, K76, and K112. SUMOylation is required for Olig2 to suppress p53-mediated cell cycle arrest and apoptosis induced by genotoxic damage, and to enhance resistance to temozolomide (TMZ) in glioma. Both SUMOylation and triple serine motif (TSM) phosphorylation of Olig2 are required for the antiapoptotic function. Olig2 SUMOylation enhances its genetic targeting ability, which in turn occludes p53 recruitment to Cdkn1a promoter for DNAdamage responses. Our work uncovers a SUMOylation-dependent regulatory mechanism of Olig2 in regulating cancer survival.
\end{abstract}

These authors contributed equally: Huiqing Liu, Weiji Weng, Rongjun Guo

Edited by A. Oberst

Supplementary information The online version of this article (https:// doi.org/10.1038/s41418-020-0569-1) contains supplementary material, which is available to authorized users.

$\triangle$ Si-Jian Pan

psj11629@rjh.com.cn

$\triangle$ Yong Li

liyong68@shsmu.edu.cn

1 Department of Biochemistry and Molecular Cell Biology, Shanghai Key Laboratory for Tumor Microenvironment and Inflammation, Shanghai Jiao Tong University School of Medicine, Shanghai 200025, China

2 Department of Physiology, School of Basic Medicine, Kunming Medical University, Kunming 650000 Yunnan, China

3 Department of Neurosurgery, Ruijin Hospital, Shanghai Jiao Tong University School of Medicine, Shanghai 200025, China

4 Department of Integrative Biology and Pharmacology, McGovern Medical School, The University of Texas Health Science Center at Houston, Houston, TX 77030, USA

\section{Introduction}

Glioblastoma (GBM) is the most common primary malignant brain tumor in adults, which displays notorious resistance to conventional therapy [1]. Transcription factors (TFs) have been shown to be critical in tumorigenesis and therapeutic resistance in GBM cells, which collectively contribute to the initiation of tumors [2-4]. In addition, the oligodendrocyte TF 2 (Olig2) has been reported to be critical in promoting proliferation, migration/invasion, and resistance to radio-/chemotherapy of glioma cells [5-7].

Olig2 is a basic helix-loop-helix (bHLH) TF expressed in neural progenitor cells (NPCs) and oligodendrocyte progenitor cells during development of the central nervous system (CNS) [8]. Olig2 plays two contrasting roles during CNS development: early on, it sustains the replication competence of NPCs, and later, it promotes cell cycle exit and specifies the formation of oligodendrocyte lineage cells from proliferating NPCs $[5,9,10]$.

Olig2 is phosphorylated at S10, S13, and S14 (also known as the triple serine motif, TSM) [11]. The phosphorylation at these sites is developmentally regulated and controls the proliferative functions of Olig2 in NPCs $[11,12]$. In addition, TSM-phosphorylated Olig2 promotes 
tumor growth in a genetically defined murine glioma model [11]. This tumorigenic function of Olig2 is correlated with its oppositional relationship to p53, where wild-type (WT) Olig2 and the triple phospho-mimetic (TPM) Olig2 (S10D/ $\mathrm{S} 13 \mathrm{E} / \mathrm{S} 14 \mathrm{E})$ repress the irradiation-induced p53 activation and expression of Cdknla (also known as p21) [6]. Moreover, a recent study showed that TSM phosphorylation serves as a regulator that switches glioma from proliferation to invasion status [7].

Posttranslational modifications (PTMs) of nuclear proteins, including TFs, nuclear receptors, and their coregulators, represent a mechanism frequently used by the cell to respond to environmental changes [13, 14]. It would be of significance to identify additional PTMs on Olig2 and learn how they interact with phosphorylation to regulate Olig2 functions. Here, we show that Olig2 is SUMOylated, a form of PTMs involving covalent enzymatic conjugation of small ubiquitin-like modifier (SUMO) proteins to specific lysine residues of substrate proteins [14]. We unveiled the critical involvement of Olig2 SUMOylation in overcoming cell cycle arrest and apoptosis in response to genotoxic drugs. Olig2 SUMOylation protects cells against genotoxic damage by disrupting the recruitment of p53 to Cdknla promoter. Thus, SUMOylation is important for Olig2 to function as an antiapoptotic factor in genotoxic stress.

\section{Materials and methods}

\section{Antibodies and reagents}

The following primary antibodies and reagents were used: mouse anti-Olig2 (MABN50, Millipore), mouse antiSUMO1 (33-2400, Thermo Fisher Scientific), mouse antiBrdU (sc-32323, Santa Cruz), mouse anti-p53 (sc-126, Santa Cruz), rabbit anti-p53 (ab32389, Abcam), mouse antiFlag (F1804, Sigma), mouse anti-Myc (sc-40, Santa Cruz), rabbit anti-Olig2 (AB9610, Millipore), rabbit anti-SUMO1 (4940, Cell Signaling Technology), rabbit anti-cleaved caspase-3 (9661, Cell Signaling Technology), rabbit antigamma H2AX (phospho S139) (ab2893, Abcam), rabbit anti-Ki67 (ab16667, Abcam), mouse anti-phosphoserine (ab6639, Abcam), rabbit anti-Olig2 (phospho S10 + S13+ S14) (ab183487, Abcam), rabbit anti-Histone H3 (4499, Cell Signaling Technology), rabbit anti-acetyl-p53 (Lys379) (2570, Cell Signaling Technology), rabbit anti-p21 (ab218388, Abcam), rabbit anti-HA (H6908, Sigma), and SUMOylation 1 Affinity Beads (ASM11, Cytoskeleton). Etoposide (ETO, E1383), temozolomide (TMZ, T2577), BrdU (B5002), and tamoxifen (TAM, T5648) were purchased from Sigma. CHIR-99021 (S2924) was purchased from Selleck.

\section{Cells and human GBM specimen}

HEK 293T, Neuro-2a, U87-MG, and HCT-116 cells were cultured in Dulbecco's Modified Eagle's Medium (DMEM) supplemented with $10 \%$ fetal bovine serum and maintained at $37{ }^{\circ} \mathrm{C}$ in a $5 \% \mathrm{CO}_{2}$ humidified incubator. Cells were transfected at 80-90\% confluency using Lipofectamine 3000 (Invitrogen) according to the manufacturer's instructions.

Human GBM tissue was acquired from Ruijin Hospital (Shanghai, China) with the approval by Ethics Committee for Clinical Trial and Medical Devices of Ruijin Hospital. Informed consent was obtained from all subjects.

\section{Plasmids}

His-SUMO1 and HA-CBP plasmids were gifts from Jianxiu $\mathrm{Yu}$ and Zhaoyuan Hou (Shanghai Jiao Tong University School of Medicine, Shanghai, China), respectively $[15,16]$. Mouse Olig2, Hdac1, p53, and Senp2 cDNA were amplified by PCR from mouse brain tissue and inserted into p3×Flag-Myc-CMV24 (Sigma), pCDNA3.1/Myc-His(-) (Invitrogen), pEGFP-C1 (Clontech), and pCMV-HA (Clontech) vectors to obtain Flag-Olig2, Myc-Olig2, MycHdac1, Flag-p53, GFP-Senp2, and HA-Senp2, respectively. HA-Sox10, HA-Olig1, and HA-Nkx2.2 were generated by inserting mouse Sox10, Olig1, and Nkx2.2 cDNA into pCDNA3 vector with an $\mathrm{HA}$ tag at the C-terminus, respectively. Myc-Sirt1 was generated by inserting human Sirt1 cDNA into pCDNA3.1/Myc-His(-) vector. Mutations of Flag/Myc-Olig2, His-SUMO1, and GFP-Senp2 were generated using PCR-directed mutagenesis and all mutations were confirmed by DNA sequencing. For luciferase reporter assay, human Cdknla promoter fragment and mouse Mycn-promoter fragment [17, 18] were amplified and cloned into pGL3-Basic vector (Promega). For lentivirus packaging, mouse Olig2 WT or 3KR cDNA was inserted into pCDH-CMV-MCS-EF1-copGFP vector (System Biosciences), with fused Myc and His tags at the Cterminus.

\section{Immunoprecipitation}

Co-immunoprecipitation (Co-IP) under nondenaturing condition was performed as previously described [19]. Briefly, cells were lysed with whole cell lysis buffer (20 mM Tris- $\mathrm{HCl}, \mathrm{pH} 7.5,150 \mathrm{mM} \mathrm{NaCl}, 1 \%$ Triton $\mathrm{X}-100$, $0.1 \%$ SDS, 2 mM EDTA, $10 \%$ glycerol) supplemented with protease inhibitor cocktail (Sigma), phosphatase inhibitor cocktail (Selleck), and $20 \mathrm{mM}$ N-ethylmaleimide (Sigma). After centrifugation for $15 \mathrm{~min}$ at $13,000 \times g$, supernatant was collected and the indicated antibody was added. Immunoprecipitants were collected with protein $\mathrm{A} / \mathrm{G}$ 
agarose (Pierce), washed three times, boiled in $2 \times$ SDS loading buffer $(50 \mathrm{mM}$ Tris- $\mathrm{HCl} \mathrm{pH} 6.8,4 \%$ 2-mercaptoethanol, $20 \%$ glycerol, $4 \%$ SDS), and subjected to western blotting analysis.

To detect SUMOylation, immunoprecipitation under denaturing conditions (De-IP) was performed as described previously [20]. Cells or tissues (mouse spinal cord or human GBM) were lysed and homogenized in SDS lysis buffer (50 mM Tris-HCl, pH 6.8, $40 \mathrm{mM}$ dithiothreitol, 5\% glycerol, $2 \%$ SDS) supplemented with protease inhibitor cocktail and $20 \mathrm{mM}$ N-ethylmaleimide. Lysates were then boiled at $95^{\circ} \mathrm{C}$ for $15 \mathrm{~min}$ and diluted to the final concentration of $0.2 \%$ SDS with dilution buffer $(50 \mathrm{mM}$ Tris$\mathrm{HCl}, \mathrm{pH} 7.5,150 \mathrm{mM} \mathrm{NaCl}, 1 \%$ Nonidet P-40) supplemented with protease inhibitor cocktail and $20 \mathrm{mM} \mathrm{N}$ ethylmaleimide. Debris was removed by centrifugation and the indicated antibody was added. After washing, immunoprecipitants were boiled in $2 \times$ SDS loading buffer and subjected to western blotting analysis with indicated antibodies.

\section{Identification of Olig2 SUMOylation site by mass spectrometry}

HEK 293T cells transfected with Flag-Olig2 and HisSUMO1 T95R were lysed with whole cell lysis buffer (20 mM Tris-HCl, pH 7.5, $150 \mathrm{mM} \mathrm{NaCl}, 1 \%$ Triton X-100, $0.1 \%$ SDS, 2 mM EDTA, $10 \%$ glycerol) supplemented with protease inhibitor cocktail, phosphatase inhibitor cocktail, and $20 \mathrm{mM}$ N-ethylmaleimide. After incubation with the anti-Flag antibody at $4{ }^{\circ} \mathrm{C}$ overnight, protein $\mathrm{A} / \mathrm{G}$ beads were added. After 1 -h incubation at $4{ }^{\circ} \mathrm{C}$, immunoprecipitants were washed sequentially with whole cell lysis buffer for four times, and with $5 \mathrm{mM} \mathrm{NH} \mathrm{NCO}_{3}$ for two times at $4{ }^{\circ} \mathrm{C}$. Proteins were eluted from the beads with $0.15 \%$ trifluoroacetic acid (Sigma). After centrifugation at $4{ }^{\circ} \mathrm{C}$ for $15 \mathrm{~min}$ at $13,000 \times \mathrm{g}$, the supernatant was collected and dried in vacuum. Eluted proteins were redissolved in $25 \mathrm{mM} \mathrm{NH} \mathrm{NH}_{4} \mathrm{HCO}_{3}$ followed by digestion with trypsin (Promega) at $37^{\circ} \mathrm{C}$ overnight. The supernatant was dried before LC-MS/MS analysis.

The samples were resuspended with $20 \mathrm{~mL}$ Buffer A (water with $0.1 \%$ formic acid) and analyzed by on-line nanospray LC-MS/MS on a Q Exactive HF (Thermo Fisher Scientific, Waltham, MA, USA) coupled to an Acquity UPLC M-class (Waters Corporation, Milford, MA, USA). Three microliters of peptide was loaded (analytical column: Waters nanoEase M/Z HSS C18 T3, $75 \mu \mathrm{m} \times 25 \mathrm{~cm}$ ) and separated with a 60 min linear gradient, from 4 to $30 \%$ Buffer B (acetonitrile with $0.1 \%$ formic acid). The column flow rate was maintained at $500 \mathrm{~nL} / \mathrm{min}$ with the column temperature of $40^{\circ} \mathrm{C}$. The electrospray voltage of $2 \mathrm{kV}$ versus the inlet of the mass spectrometer was used.
The mass spectrometer was run under data dependent acquisition mode, and automatically switched between MS and MS/MS mode. The parameters were: (1) MS: scan range $(\mathrm{m} / \mathrm{z})=350-1600 ; \quad$ resolution $=60,000 ; \quad$ AGC target $=3 \mathrm{e} 6$; maximum injection time $=50 \mathrm{~ms}$; include charge states $=2-7 ;$ (2) HCD-MS/MS: resolution $=15,000$; isolation window $=1.6 ; \quad$ AGC target $=1 \mathrm{e} 5 ;$ maximum injection time $=100 \mathrm{~ms}$; collision energy $=30$.

Tandem mass spectra were processed by PEAKS Studio version X (Bioinformatics Solutions Inc, Waterloo, ON, Canada). PEAKS DB was set up to search the uniprot_proteome_mus_musculus_201907 database (ver 201907, 22290 entries) assuming trypsin as the digestion enzyme. PEAKS DB was searched with a fragment ion mass tolerance of $0.02 \mathrm{Da}$ and a parent ion tolerance of $7 \mathrm{ppm}$. Oxidation (M), carbamidomethylation (C), N-ethylmaleimide (C), nethylmaleimidehydrolysis (C), and GG modification (K) were specified as the variable modifications. The peptides with $-10 \lg P \geq 20$ and the proteins with $-10 \lg P \geq 20$ and containing at least one unique peptide were filtered.

\section{Cycloheximide (CHX) chase assays}

Protein degradation was assessed by CHX (Sigma) chase assay as described previously [19]. CHX was added to the culture medium $(20 \mu \mathrm{g} / \mathrm{mL}$ final concentration) $24 \mathrm{~h}$ post transfection, samples were taken at the indicated time points, and steady-state levels of protein of interest were determined by western blotting with appropriate antibodies as indicated.

\section{Nuclear extraction}

Nuclear fraction was isolated as previously described with minor modifications [12]. Briefly, cell pellets were resuspended with hypotonic buffer $(20 \mathrm{mM}$ Tris-HCl, $\mathrm{pH} 7.4$, $10 \mathrm{mM} \mathrm{NaCl}, 3 \mathrm{mM} \mathrm{MgCl} 2$ ). Homogenates were incubated on ice for $15 \mathrm{~min}$ and then $10 \%$ Nonidet P-40 was added to a final concentration of $0.5 \%$. After centrifugation at $700 \times$ $g$ for $10 \mathrm{~min}$, supernatant was collected as the cytoplasmic fraction. The pellet was washed with hypotonic buffer and then lysed with whole cell lysis buffer $(20 \mathrm{mM}$ Tris-HCl, pH 7.5, $150 \mathrm{mM} \mathrm{NaCl}, 1 \%$ Triton X-100, 0.1\% SDS, $2 \mathrm{mM}$ EDTA, $10 \%$ glycerol). After centrifugation at $13,000 \times g$ for $10 \mathrm{~min}$, supernatant was taken as the nucleus fraction. Protein concentration was quantitated using a BCA assay kit (Thermo Fisher Scientific). All buffers were supplemented with protease inhibitor cocktail, phosphatase inhibitor cocktail, $1 \mathrm{mM}$ PMSF, and $0.5 \mathrm{mM}$ dithiothreitol.

\section{Luciferase reporter assay}

Construction of the plasmids for luciferase reporter assay was described above. The Cdknla- or Mycn-promoter 
luciferase plasmids were cotransfected with Renilla luciferase plasmid, WT Flag-Olig2, 3KR Flag-Olig2, AQ FlagOlig2, and/or His-SUMO1 into Neuro-2a cells using Lipofectamine 3000 . At $24 \mathrm{~h}$ post transfection, cells were harvested and analyzed for the luciferase activity using a dual-luciferase reporter assay kit (Promega) following the manufacturer's instructions. The luciferase activity for each group was normalized with Renilla luciferase activity. See also [5].

\section{Lentivirus packaging}

Olig2-expressing lentiviral constructs were generated as described above. Lentivirus packaging was performed by OBiO Technology Co. Ltd (Shanghai, China). U87-MG cells were stably infected with Lenti-GFP $\left(1.63 \times 10^{9}\right.$ $\mathrm{TU} / \mathrm{mL})$, Lenti-Olig2 ${ }^{\mathrm{WT}}\left(1.38 \times 10^{9} \mathrm{TU} / \mathrm{mL}\right)$, and LentiOlig2 $2^{3 \mathrm{KR}}\left(1.17 \times 10^{9} \mathrm{TU} / \mathrm{mL}\right)$, respectively, [21].

\section{TUNEL staining}

TUNEL staining was performed using an in situ cell death detection kit (Roche) following the manufacturer's instructions. Briefly, cells were fixed with $4 \%$ paraformaldehyde $/ 4 \%$ sucrose and permeabilized in $0.1 \%$ Triton $\mathrm{X}-100$ in phosphate-buffered saline (PBS). After washing with PBS, cells were then incubated in the reaction solution containing terminal deoxynucleotidyl transferase and nucleotide mixture at $37^{\circ} \mathrm{C}$ for $1 \mathrm{~h}$. See also [22].

\section{Immunofluorescence and confocal microscopy}

Immunofluorescence staining was performed as described previously [20]. Briefly, cells were fixed with $4 \%$ paraformaldehyde $/ 4 \%$ sucrose, blocked in $5 \%$ goat serum and $0.1 \%$ Triton X-100 (in PBS), and incubated with indicated primary antibodies overnight. Cells were then rinsed in PBS three times and incubated with appropriate fluorescenceconjugated secondary antibodies. After washing with PBS three times, cells were incubated with DAPI and mounted using Fluoromount-G (SouthernBiotech). For BrdU staining, cells were incubated with $10 \mu \mathrm{M}$ BrdU for $1 \mathrm{~h}$ prior to fixation. After fixation, cells were incubated in $2 \mathrm{M} \mathrm{HCl}$ for $10 \mathrm{~min}$ at room temperature, followed by neutralization with PBS. Confocal images were obtained using a Leica SP8 confocal microscopy system (Leica Microsystems Inc., Buffalo Grove, IL, USA).

\section{Chromatin immunoprecipitation (ChIP)}

ChIP was performed using an EZ-ChIP chromatin immunoprecipitation kit (Millipore) with minor modifications [21]. In brief, ETO-treated cells were fixed with $1 / 10$ volume of $11 \%$ formaldehyde solution (50 mM HEPES$\mathrm{KOH}, \mathrm{pH} 7.5,100 \mathrm{mM} \mathrm{NaCl}, 1 \mathrm{mM}$ EDTA, $0.5 \mathrm{mM}$ EGTA, $11 \%$ formaldehyde). Cells were then harvested and lysed in SDS lysis buffer (50 mM Tris- $\mathrm{HCl}, \mathrm{pH} 8.1,10 \mathrm{mM}$ EDTA, 1\% SDS) supplemented with protease inhibitor cocktail and $20 \mathrm{mM}$ N-ethylmaleimide. The lysates were sonicated and centrifugated to remove cellular debris. Samples were diluted with ChIP dilution buffer $(16.7 \mathrm{mM}$ Tris-HCl, pH 8.1, $167 \mathrm{mM} \mathrm{NaCl}, 1.2 \mathrm{mM}$ EDTA, $0.01 \%$ SDS, $1.1 \%$ Triton X-100) supplemented with protease inhibitor cocktail and $20 \mathrm{mM}$ N-ethylmaleimide, after which $1 \%$ input was taken. DNA/protein complex was immunoprecipitated with the anti-Flag antibody or anti-p53 antibody. Normal mouse IgG was used as the negative control. Immunoprecipitants were pulled down with ChIP blocked protein $\mathrm{G}$ agarose (Millipore) and then washed sequentially with low salt wash buffer $(20 \mathrm{mM}$ Tris- $\mathrm{HCl}$, pH 8.1, $150 \mathrm{mM} \mathrm{NaCl}, 2$ mM EDTA, 0.1\% SDS, $1 \%$ Triton $\mathrm{X}-100)$, high salt wash buffer $(20 \mathrm{mM}$ Tris-HCl, $\mathrm{pH} 8.1$, $500 \mathrm{mM} \mathrm{NaCl}, 2 \mathrm{mM}$ EDTA, $0.1 \%$ SDS, $1 \%$ Triton $\mathrm{X}$ 100), $\mathrm{LiCl}$ wash buffer (10 mM Tris-HCl, $\mathrm{pH} 8.1,0.25 \mathrm{M}$ LiCl, $1 \mathrm{mM}$ EDTA, 1\% Nonidet P-40, 1\% deoxycholic acid), and TE buffer (10 mM Tris- $\mathrm{HCl}, \mathrm{pH} 8.0,1 \mathrm{mM}$ EDTA). Samples were then eluted with elution buffer (1\% SDS, $100 \mathrm{mM} \mathrm{NaHCO} 3$ ). Eluates were incubated at $65^{\circ} \mathrm{C}$ overnight in the presence of $200 \mathrm{mM} \mathrm{NaCl}$ to reverse the crosslinked DNA. Free DNA was purified with a DNA purification kit (Tiangen, Beijing, China), followed by quantitative PCR in LightCycler 480 PCR system (Roche, Basel, Switzerland) using SYBR Green mix (Vazyme, Nanjing, China).

Primers used for the ChIP assay were as follows: human Cdknla distal forward GGGCTTTCCACCTTTCACC, reverse ACCATCCCCTTCCTCACCT; proximal forward GGGCAGGAGGCAAAAGTCCT, reverse GAAGCCTGT CCTCCCCGAGG; non-target forward TCTGTGAAAACATGCCCAGC, reverse TTGAAACAGGGGACCGTG TC; human Bax forward CTCTCGGACCCTCGAGAAC, reverse AGGCTGGGCCTGTATCCTAC; mouse Cdknla forward AGGTCAGCTAAATCCGAGGAGGAA, reverse TCCTGCTTTGGAGAAGCTGTAGT; $E g f r$ forward GTG GTCCCAATTTCCTGCTG, reverse ATGGAGCTCATGGACCTCATTG; $F g f r 3$ forward TAGACCCCCACCGA AGTCAA, reverse, GACTGTCTACCAGCACGCTT; Tgfb2 forward, CTCCTGCAGCTCTGTTGTGA, reverse TTTATTTCTTTGCTTGCTTGCTTT.

\section{Quantitative PCR}

Total RNA was extracted from ETO-treated Neuro-2a cells using TRNzol-A + reagent (Tiangen, Beijing, China) as described previously [23]. An aliquot of RNA $(2 \mu \mathrm{g})$ was used for cDNA synthesis using PrimeScript RT reagent kits 
with gDNA Eraser (Takara). cDNA was then analyzed in LightCycler 480 PCR system (Roche, Basel, Switzerland) using SYBR Green mix (Vazyme, Nanjing, China). The primer for Cdknla quantitation was as follows: mouse Cdknla forward CCTGGTGATGTCCGACCTG, reverse CCATGAGCGCATCGCAATC; human Cdknla forward TGTCCGTCAGAACCCATGC, reverse AAAGTCGAAG TTCCATCGCTC.

\section{Colony formation assay}

U87-MG cells stably expressing GFP vector, WT MycOlig2, or 3KR Myc-Olig2 were plated at 1000 cells per 60 $\mathrm{mm}$ dish, followed by treatment with $200 \mu \mathrm{M} \mathrm{TMZ}$ for $24 \mathrm{~h}$, after which cells were allowed to grow for 6-7 days in normal culture medium. Colonies were fixed with $4 \%$ paraformaldehyde and stained with $0.1 \%$ crystal violet for 15 min. One colony is defined to consist of over 50 cells [24].

\section{Animal experiments}

A total of $2 \times 10^{6}$ U87-MG cells were injected into the flank of 6-week-old $\mathrm{BALB} / \mathrm{c}$ nude mice to generate model of GBM [25]. When tumors reached the size of approximal $500 \mathrm{~mm}^{3}$, animals were treated with TMZ $(40 \mathrm{mg} / \mathrm{kg}$, i.p) for 5 consecutive days and tumor size was monitored every 3 days. Tumor volumes were calculated using the formula (length $\times$ width $\left.^{2}\right) / 2$.

To generate intracranial GBM xenografts, $5 \times 10^{5}$ U87MG cells in DMEM $(5 \mu \mathrm{L})$ were injected into the brains of 6-week-old BALB/c nude mice at a rate of $0.2 \mu \mathrm{L} / \mathrm{min}$. The coordinates are as follows: $2 \mathrm{~mm}$ lateral (right), $1 \mathrm{~mm}$ anterior, and $3 \mathrm{~mm}$ ventral (according to bregma). Animals were treated with TMZ $(40 \mathrm{mg} / \mathrm{kg}$, i.p) for 5 consecutive days after 15 days post transplantation.

For histological analysis and immunostaining of orthotopically grafted tumors, mice were sacrificed 5-7 days post TMZ administration. Brains were fixed with $4 \%$ paraformaldehyde, cryoprotected in 30\% sucrose, and embedded in OCT (TissueTek, Sakura). Cryostat sections $(12 \mu \mathrm{m}$ thickness) were made and used for staining.

All animal protocols were in accordance with the guidelines established by the Care and Use of Laboratory Animals of Shanghai Jiao Tong University School of Medicine and approved by the Institutional Animal Care and Use Committee.

\section{Statistical analysis}

All data are presented as means \pm s.e.m. of at least three independent experiments, with statistical significance assessed by Student's $t$ test for two group comparison, oneway ANOVA or two-way ANOVA with Tukey's multiple comparison test for multiple group comparisons. Statistical significance is defined as $p<0.05$. $\left(* p<0.05,{ }^{*} p<0.01\right.$, $* * * p<0.001$.)

\section{Results}

\section{Olig2 is modified by SUMO1}

Many TFs or coregulators of transcription are SUMO substrates, and in most cases, modification with SUMO results in transcriptional repression [26, 27]. De-IP analysis showed that the anti-Flag antibody pulled down, in addition to Flag-Olig2 ( $42 \mathrm{kD})$, two higher molecular weight bands $\sim 18$ and $25 \mathrm{kD}$ larger than the unmodified Olig2 protein, indicating that Olig2 is SUMOylated. Reciprocally, the antiFlag antibody also pulled down the similar two higher molecular weight bands detectable by the anti-Olig2 antibody (Fig. 1b). Importantly, the SUMOylated Olig2 bands were abolished by co-expression of the SUMO deconjugating enzyme GFP-Senp2 (Senp2 ${ }^{\mathrm{WT}}$ ), but not the catalytically dead Senp2 mutant (Senp2 ${ }^{\mathrm{CS}}$, C547S) (Fig. 1a, b).

Next, to test whether Olig2 is conjugated by endogenous SUMO1, lysates from HEK 293T cells transiently transfected with Flag-Olig2 were subjected to De-IP and immunoblotted with the anti-SUMO1 and anti-Olig2 antibodies. In both cases, a band corresponding to the predicted size of SUMO1-conjugted Olig2 was detected (Fig. 1c). Using DeIP in lysates prepared from mouse spinal cord tissue and human GBM, we detected a weak but nonetheless clear band of $\sim 52 \mathrm{kD}$, which corresponds to the estimated molecular weight of SUMOylated Olig2 ( $\sim 37 \mathrm{kD}$ for the endogenous Olig2 plus $\sim 15 \mathrm{kD}$ for SUMO1) (Fig. 1d, e). In SUMOylated proteins enriched by SUMO1 affinity beads from mouse spinal cord lysates, we also observed the same sized band (Fig. S1A). With the addition of the Flag epitope, Flag-Olig2 becomes $\sim 5 \mathrm{kD}$ larger (net weight of $\sim 42 \mathrm{kD}$ ) than endogenous Olig2 (Fig. S1B), giving rise to the SUMOylated Flag-Olig2 of $\sim 57 \mathrm{kD}$ (Fig. 1c). Because of the additional amino acids added in the epitope-tagged SUMO1, the SUMOylated-Olig2 appeared even larger $(\sim 60 \mathrm{kD})$ in Fig. 1a, b. The weaker upper band detected in Fig. 1a, b probably represents additional PTM of the SUMOylatedOlig2 species, which may be too weak to be detectable in the absence of SUMO1 overexpression (Figs. 1c-e and S1A). Taken together, these results suggest that Olig2 is SUMOylated both in vitro and in vivo.

\section{K27/K76/K112 are the major SUMOylation sites in Olig2}

Protein SUMOylation typically occurs at lysine residues located within the consensus sequence $\Psi-\mathrm{K}-\mathrm{X}-\mathrm{E}$, where $\Psi$ 

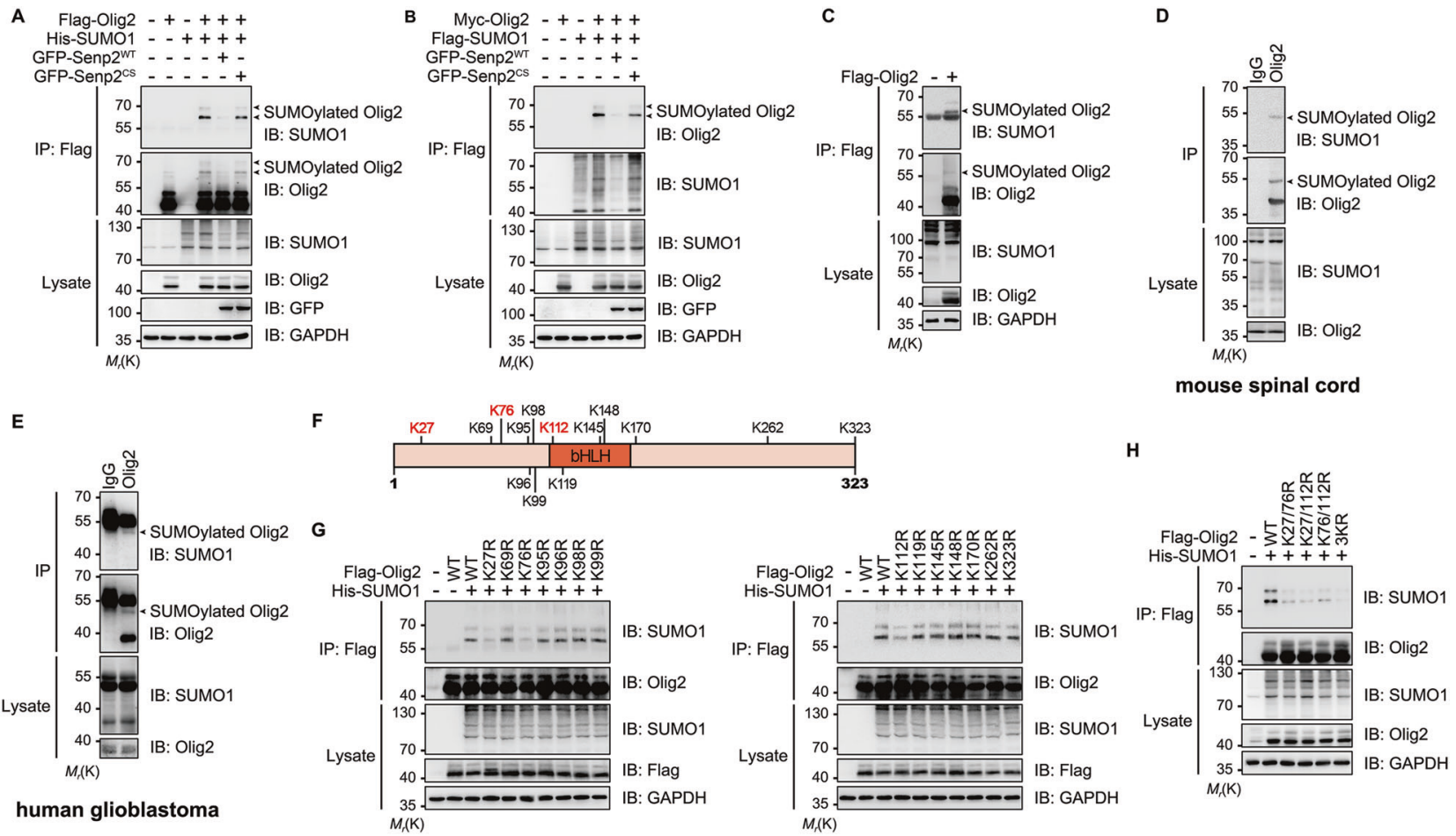

Fig. 1 Olig2 is modified by SUMO1 at K27, K76, and K112. a SUMO1 modification of Olig2 in HEK 293T cells. HEK 293T cells were transfected with Flag-Olig2, His-SUMO1, GFP-Senp2 ${ }^{\mathrm{WT}}$, or GFP-Senp $2{ }^{\mathrm{CS}}$. Cell lysates were prepared under denaturing conditions and immunoprecipitated with anti-Flag antibody and then immunoblotted using rabbit anti-Olig2 and rabbit anti-SUMO1 antibodies. b Similar to a for reciprocal immunoprecipitation. HEK 293T cells were transfected with Myc-Olig2, Flag-SUMO1, GFP-Senp2 ${ }^{\text {WT }}$, or GFP-Senp $2^{\text {CS }}$. Cell lysates were immunoprecipitated using anti-Flag antibody and then immunoblotted with rabbit anti-Olig2 and rabbit anti-SUMO1 antibodies. c Olig2 is modified by endogenous SUMO1. HEK 293T cells were transfected with or without Flag-Olig2. Cell lysates were immunoprecipitated with anti-Flag antibody, followed by immunoblotting using rabbit anti-Olig2 and rabbit anti-SUMO1

is any hydrophobic amino acid and $\mathrm{X}$ is any amino acid [28]. However, no consensus SUMOylation sequence was found in Olig2 with the use of three SUMOylation prediction programs, GPS-SUMO [29], SUMO plot (http://www. abgent.com/sumoplot), and JASSA (Fig. S1C) [30]. Given that there are only 14 lysine residues in mouse Olig2 (Fig. 1f), we decided to substitute all of them individually with arginines and then test how the mutations affect SUMO1 conjugation. Among the 14 substitutions, only $\mathrm{K} 27 \mathrm{R}, \mathrm{K} 76 \mathrm{R}$, and $\mathrm{K} 112 \mathrm{R}$ resulted in marked reduction, but not complete loss, of Olig2 SUMOylation, as compared with WT Olig2 (Fig. 1g). To confirm these modifications, we purified Olig2 proteins co-expressed with His-SUMO1 T95R by De-IP and subjected them to LC-MS/MS analysis. The T95R substitution allows SUMO1 to be cleaved by trypsin to generate a diglycine (GG) tag conjugated on the SUMOylated lysine $[31,32]$. The results showed a GG tag on tryptic peptides containing $\mathrm{K} 27$ and K76, confirming antibodies. d, e Olig2 is modified by SUMO1 in vivo. Mouse spinal cord tissue or human glioblastoma tissue were homogenized and lysed under denaturing conditions, followed by immunoprecipitation with mouse anti-Olig2 antibody. Rabbit anti-SUMO1 and rabbit anti-Olig2 antibodies (d) or mouse anti-SUMO1 and mouse anti-Olig2 antibodies (e) were used for western blotting analysis. f Schematic showing lysine residues in mouse Olig2. $\mathbf{g}$, $\mathbf{h}$ Identification of Olig2 SUMOylation sites. The indicated $\mathrm{K} \rightarrow \mathrm{R}$ mutants were transfected into HEK 293T cells with His-SUMO1. Cell lysates were subsequently immunoprecipitated using anti-Flag antibody and immunoblotted with rabbit anti-Olig2 and rabbit anti-SUMO1 antibodies. For all panels, arrowheads indicate SUMOylated Olig2. Blot images shown are representative of at least three independent experiments.

that K27 and K76 are SUMOylated (Fig. S2A, B). To test the contribution of $\mathrm{K} 112$, as well as $\mathrm{K} 27$ and $\mathrm{K} 76$, to the overall SUMOylation of Olig2, we made double mutations, i.e., $\mathrm{K} 27 / 76 \mathrm{R}, \mathrm{K} 27 / 112 \mathrm{R}$, and $\mathrm{K} 76 / 112 \mathrm{R}$, as well as a triple mutation, K27/76/112R (3KR). All double mutations resulted in marked reduction but not complete loss of Olig2 SUMOylation, whereas 3KR exhibited the lowest level of SUMOylation among all constructs tested (Figs. 1h and S1E). Importantly, K27, K76, and K112 are well-conserved among mammalian Olig2 orthologs (Fig. S1D). Based on findings, we conclude that Olig2 is SUMOylated at K27, $\mathrm{K} 76$, and K112.

\section{Olig2 SUMOylation is required for inhibition of DNA- damage response}

Olig2 is reported to be a protective TF against p53-mediated cell cycle arrest and apoptosis upon irradiation-induced 
A
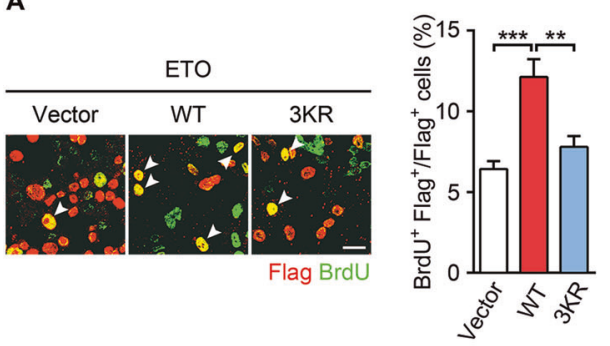

C

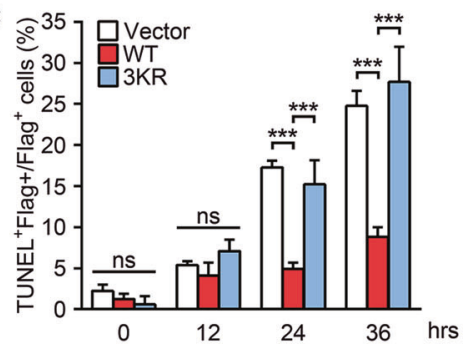

B

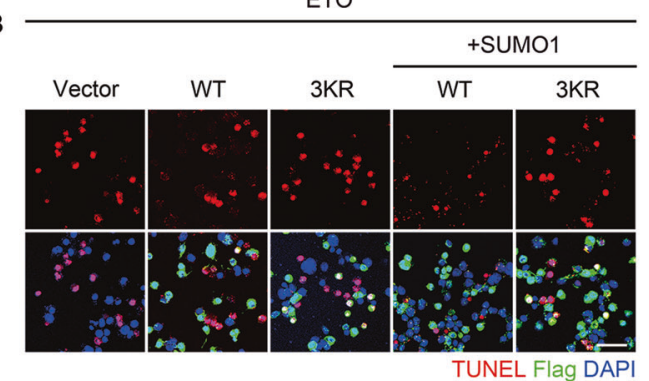

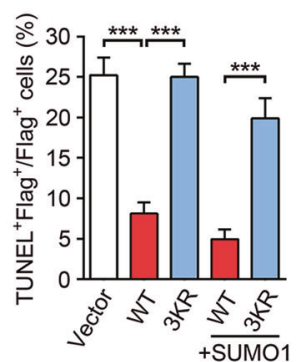

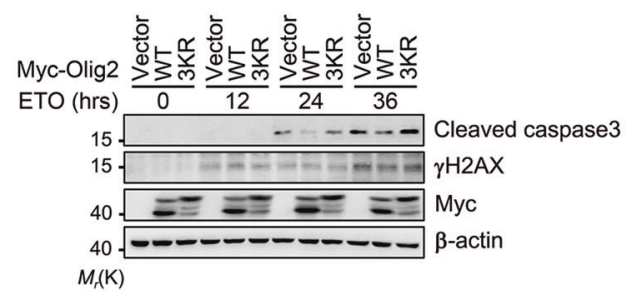

Fig. 2 Olig2 SUMOylation is required for inhibition of DNAdamage response. a Representative images of $\mathrm{BrdU}^{+}$(green) uptake in Flag-Olig2 expressing (red) Neuro-2a cells. Cells transfected with vector, WT, or 3KR Flag-Olig2 were incubated with $20 \mu \mathrm{M}$ etoposide (ETO) for $36 \mathrm{~h}$ and then pulsed with $10 \mu \mathrm{M}$ BrdU for $1 \mathrm{~h}$. Immunostaining was performed using anti-BrdU and anti-Flag antibodies. The bar graphs represent the percentage of $\mathrm{BrdU}^{+} / \mathrm{Flag}^{+}$cells. Scale bar $=$ $25 \mu \mathrm{m}$. b Representative images of TUNEL (red) staining in FlagOlig2 expressing (green) Neuro-2a cells. Cells transfected with vector, WT, or 3KR Flag-Olig2 were incubated with $20 \mu \mathrm{M}$ ETO for $36 \mathrm{~h}$. Cells were then subjected to TUNEL staining and immunostaining using anti-Flag antibody. The bar graphs represent the percentage of TUNEL $^{+}$among Flag ${ }^{+}$cells. Scale bar $=50 \mu \mathrm{m}$. c, d WT Olig2 represses genotoxic drug-induced apoptosis. Neuro-2a cells overexpressing vector, WT, or 3KR Myc-Olig2 were incubated with $20 \mu \mathrm{M}$

genotoxic damage [6]. In neuroblastoma Neuro-2a cells treated with ETO, a widely used antitumor agent [33], the number of $\mathrm{BrdU}^{+}$cells was significantly higher in cells that overexpressed WT Olig2 than those transfected with the 3KR mutant (Fig. 2a), which argues for an essential role of SUMOylation in the protective effect of Olig2 against cell cycle arrest. To assess the functional significance of SUMOylation on the ability of Olig2 against tumor apoptosis, we measured apoptotic responses of the ETO-treated Neuro-2a cells. As shown in Fig. 2b, c, overexpression of WT Olig2 in Neuro-2a cells resulted in a decrease of TUNEL $^{+}$cells, consistent with previous studies [6, 12]. However, overexpression of $3 \mathrm{KR}$ failed to show any protection no matter if SUMO1 was co-expressed or not (Fig. 2b, c). On the other hand, overexpression of WT Olig2 resulted in a decrease in the cleaved caspase- 3 in cells treated with ETO for 24 and $36 \mathrm{~h}$, while that of $3 \mathrm{KR}$ failed to show any protection (Fig. 2d). These data further support the conclusion that SUMOylation is required for the protection of Olig2 against apoptosis.
ETO for indicated periods. Cells were then subjected to TUNEL staining (c) or lysed for western blotting analysis using anti-cleaved caspase- 3 and anti- $\gamma \mathrm{H} 2 \mathrm{AX}$ antibodies (d). Results shown are representatives of at least three independent experiments. Bar graphs are presented as means \pm s.e.m. of at least three independent experiments. Statistical significance was assessed by one-way ANOVA with Tukey's multiple comparison test $(\mathbf{a}, \mathbf{b}, \mathbf{d})$ or two-way ANOVA (c) for multiple group comparisons. ${ }^{*} p<0.05 ; * * p<0.01 ; * * * p<0.001$; ns nonsignificant. Note: the green fluorescence signal of cells expressing the Flag vector is always much weaker than that of cells expressing Flag-Olig2. In this series of experiments, including Figs. 2b, 2c, 5a and $\mathrm{S} 3 \mathrm{~A}$, we routinely use the same low laser power and other parameter settings of our confocal system to acquire images for all samples.

\section{SUMOylation is required for Olig2-mediated resistance to $T M Z$ in glioma}

TMZ, a DNA alkylating agent, is now a standard-of-care chemotherapeutic agent for adult patients with recurrent high-grade glioma [1]. In order to test whether Olig2 SUMOylation plays a role in TMZ resistance of glioma, we employed human GBM U87-MG cells which endogenously express WT p53 but not Olig2 (Fig. S1B) [21, 34]. U87MG cell lines stably expressing, respectively, WT and $3 \mathrm{KR}$ Myc-Olig2 at comparable levels were established (Fig. 3a) and then treated with TMZ. Consistently, disruption of the three SUMOylation sites in Olig2 also abolished its protective effect against genotoxic damage (Fig. 3b). In addition, while the expression of WT Olig2 increased viability of TMZ-treated cells (Fig. 3c), the expression of 3KR did not have such an effect (Fig. 3c). To assess the function of Olig2 SUMOylation in vivo, we injected the stable U87MG cells either subcutaneously or intracranially into nude mice as illustrated (Fig. 3d, e). The animals were treated 
A

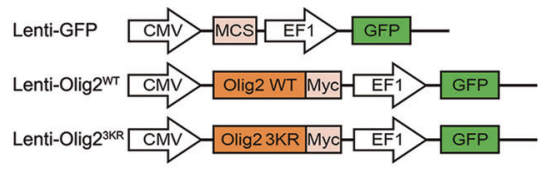

C

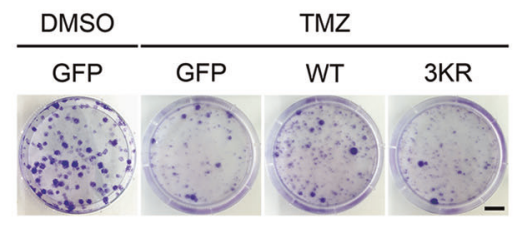

D

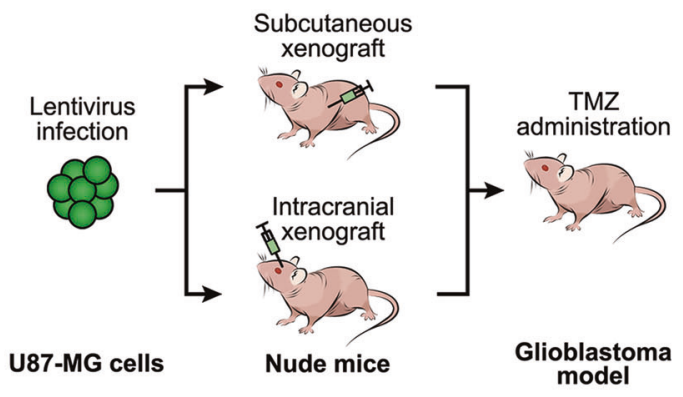

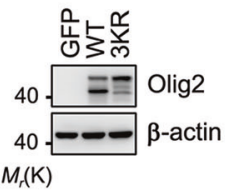

B

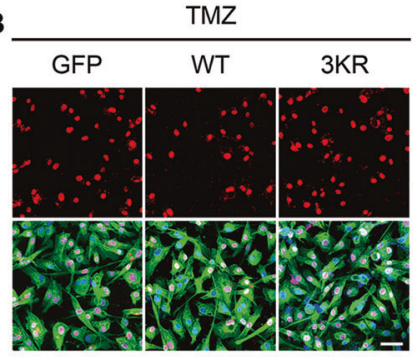

TUNEL GFP DAPI

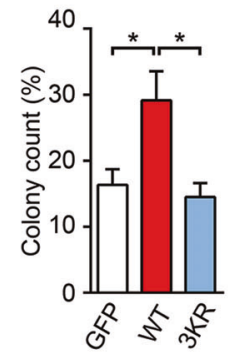

model

E

$\mathbf{F}$
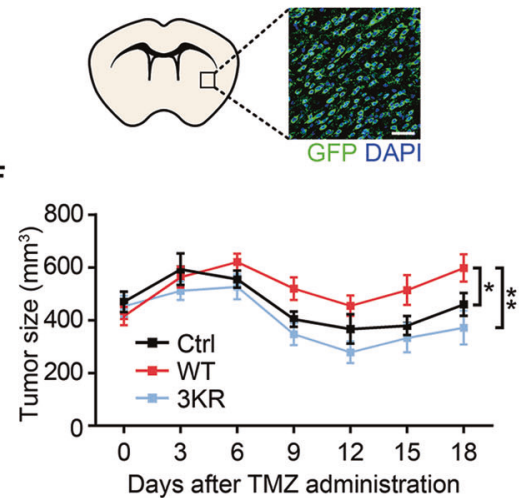

G
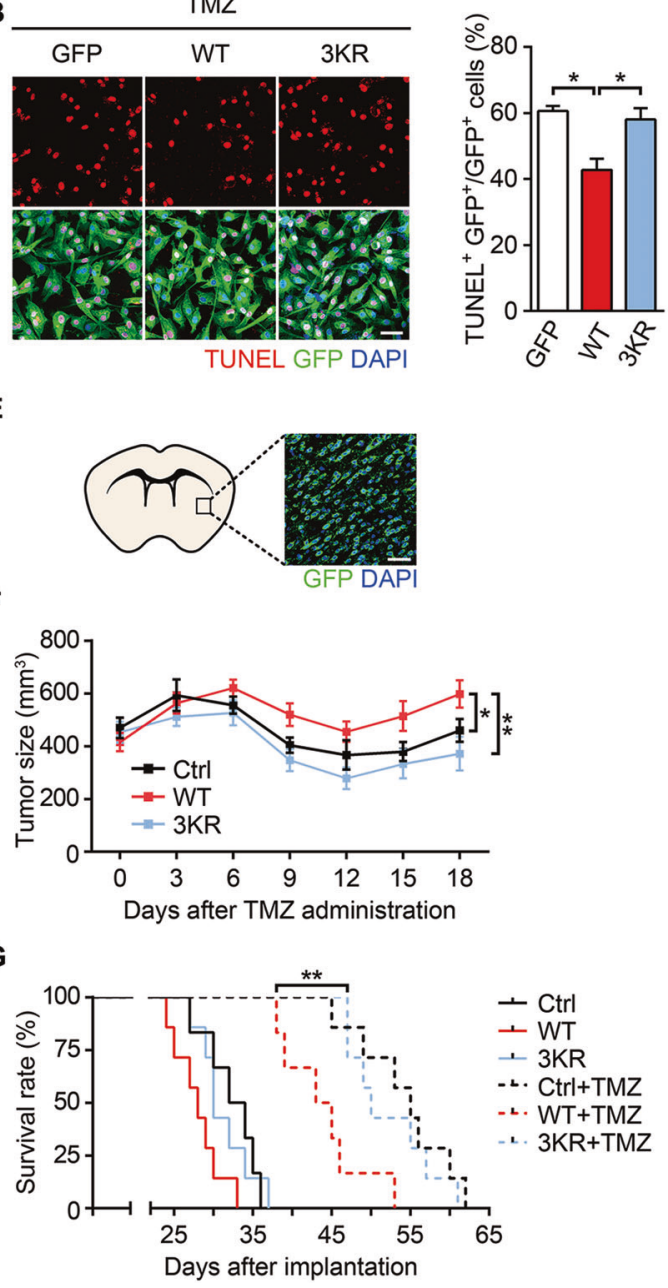

brain. f TMZ inhibits the growth of gliomas expressing GFP or $3 \mathrm{KR}$ Olig2, but not those expressing WT Olig2. U87-GFP, U87-Olig2 ${ }^{\text {WT }}$, or U87-Olig $2^{3 \mathrm{KR}}$ cells $\left(2 \times 10^{6}\right)$ were subcutaneous injected into 6-weekold nude mice ( $\mathrm{Ctrl}, n=6$; WT, $n=6 ; 3 \mathrm{KR}, n=5$ ). When tumor size reached the volume of about $500 \mathrm{~mm}^{3}$, mice were administered with $40 \mathrm{mg} / \mathrm{kg}$ TMZ for 5 consecutive days, and tumor size was then evaluated every 3 days. g Kaplan-Meier survival analysis of intracranial glioblastoma model mice. U87-GFP, U87-Olig2 ${ }^{\mathrm{WT}}$, or U87Olig $2^{3 \mathrm{KR}}$ cells $\left(5 \times 10^{5}\right)$ were intracranially injected into 6-week-old nude mice (Ctrl, $n=6$; WT, $n=7 ; 3 \mathrm{KR}, n=7$; Ctrl + TMZ, $n=7$; $\mathrm{WT}+\mathrm{TMZ}, n=6 ; 3 \mathrm{KR}+\mathrm{TMZ}, n=7)$. At 15 days post transplantation, mice were administered with $40 \mathrm{mg} / \mathrm{kg}$ TMZ for 5 consecutive days. Summary graphs are presented in means \pm s.e.m. Statistical significance was assessed by one-way ANOVA (b, c) or two-way ANOVA test for multiple group comparisons (f) or log-rank test for survival analysis $(\mathbf{g}) . * p<0.05 ; * * p<0.01$.

large extend (Fig. 3f). In the intracranial xenograft model, TMZ administration greatly improved the survival of mice bearing either control (GFP) or 3KR expressing tumors, with the prolonged median survival of 50 days; however, this effect was compromised by the expression of WT Olig2, resulting in a reduction of median survival to 44 days (Fig. 3g). 
A

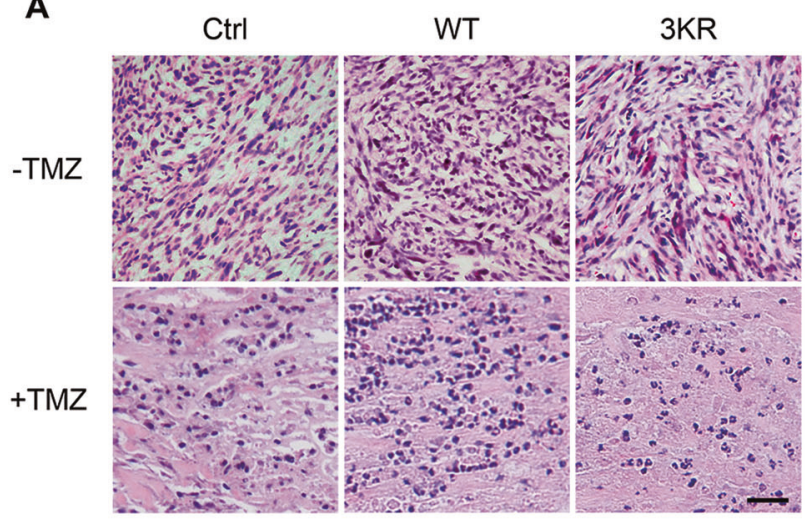

C

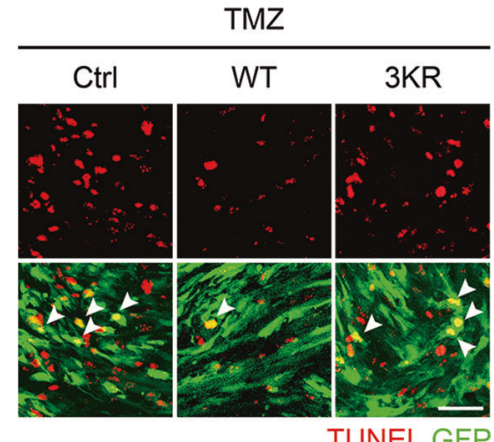

Fig. 4 Olig2 SUMOylation inhibits apoptosis in orthotopic xenografts. Intracranial glioblastoma models of Olig2-expressing tumors were created in mice as described in Fig. 3d. Transplanted nude mice were treated with saline $(-\mathrm{TMZ})$ or TMZ $(+\mathrm{TMZ})$ and sacrificed 5-7 days later. a Representative images of H\&E staining of the tumors. Frozen sections were prepared and subjected to H\&E staining. Scale bar $=50 \mu \mathrm{m}$. b, d Olig2 SUMOylation promotes tumor proliferation after TMZ administration. Proliferating cells were labeled by Ki67 staining. The bar graph in $\mathbf{d}$ shows the percentage of $\mathrm{Ki}^{+}{ }^{+}$(red)

In addition, H\&E stains of tumor sections showed that orthotopic grafts expressing 3KR Olig2 had much more severe cell loss as compared with those expressing WT Olig2 (Fig. 4a). Tumors expressing WT Olig2 showed a higher proliferation rate (Fig. 4b, d) and a lower apoptosis rate (Fig. 4c, e) than the control counterpart and those expressing 3KR Olig2. Taken together, our results demonstrate that SUMOylation constitutes a pivotal step of Olig2 PTMs for establishing the TMZ resistance in GBM and disrupting Olig2 SUMOylation may have survival benefit in glioma therapy.

\section{Both SUMOylation and TSM phosphorylation are required for the antiapoptotic function of Olig2}

The mitogenic and anti-p53 functions of Olig2 are known to be regulated by phosphorylation of TSM [6, 12]. TSMphosphorylated Olig2 is associated with a transcriptionally active chromatin fraction, where it regulates target gene
B

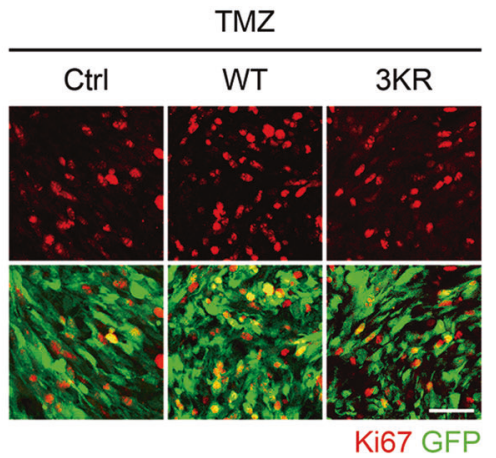

D

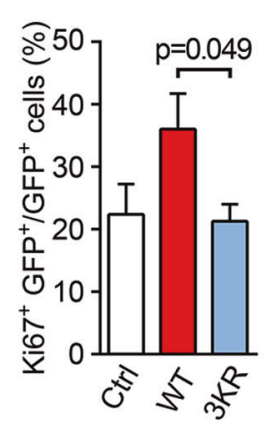

E

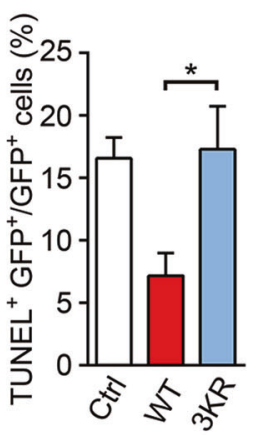

among $\mathrm{GFP}^{+}$(green) cells. Scale bar $=50 \mu \mathrm{m}$. c, e Olig2 SUMOylation inhibits tumor apoptosis after TMZ administration. Cells undergoing apoptosis were labeled by TUNEL staining. The bar graph in e shows the percentage of $\mathrm{TUNEL}^{+}$(red) among $\mathrm{GFP}^{+}$(green) cells. Images shown are representatives of at least three independent experiments. Bar graphs are presented as means \pm s.e.m. of at least three independent experiments. Statistical significance was assessed by one-way ANOVA with Tukey's multiple comparison test. $* p<0.05$.

expression [12]. Interestingly, only overexpression of WT or triple phospho-mimetic Olig2 resulted in protection of Neuro-2a cells from ETO-induced apoptosis. Disrupting either SUMOylation (with 3KR) or TSM phosphorylation (with the triple phospho-null mutant, TPN) was sufficient to completely abolish the protective effect of Olig2 and more importantly, the loss of SUMOylation even diminished the protective effect of TPM (with phosphorylationSUMOylation double mutant, 3KR-TPM) (Figs. 5a and S3A), indicating that neither SUMOylation nor TSM phosphorylation alone was sufficient to support the antiapoptotic effect of Olig2.

Immunoblotting shows that the phosphorylation of TSM was similar between WT and 3KR (Fig. 5b). For both WT and 3KR Olig2, the TSM phosphorylation levels were unaffected by the co-expression of His-SUMO1, MycUbc9, or HA-Senp2, despite the marked increase in SUMOylation caused by the SUMO conjugating enzyme, Ubc9, and the decrease in SUMOylation resulted from 


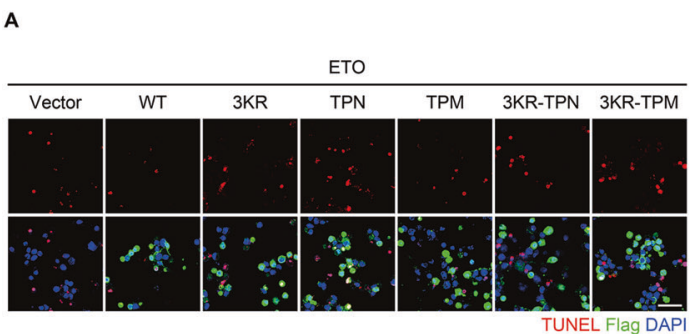

c

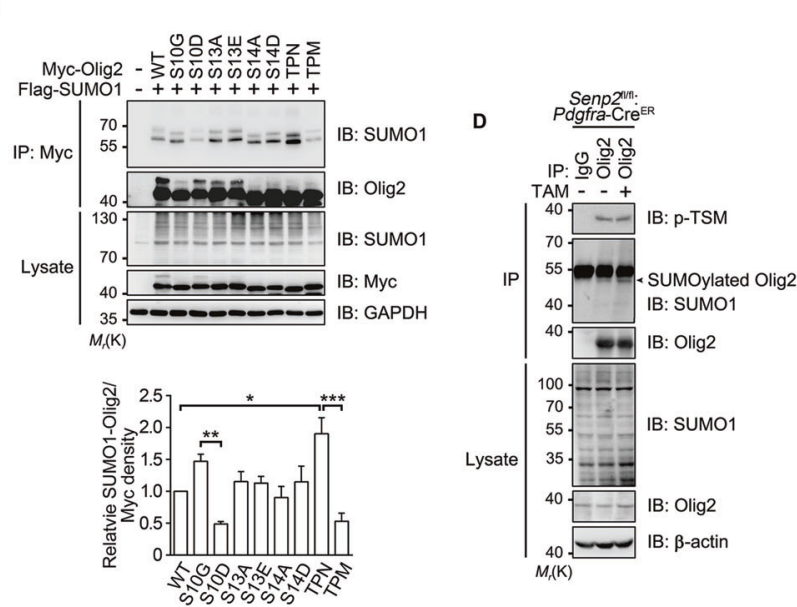

Fig. 5 Crosstalk between Olig2 SUMOylation and phosphorylation. a Representative images of TUNEL (red) staining in Flag-Olig2 expressing (green) Neuro-2a cells. Neuro-2a cells overexpressing Flag-Olig2 (WT, 3KR, TPN, TPM, 3KR-TPN and 3KR-TPM) were incubated with $20 \mu \mathrm{M}$ ETO for $36 \mathrm{~h}$, followed by TUNEL staining and immunostaining using anti-Flag antibody. The bar graph shows the percentage of $\mathrm{TUNEL}^{+}$among Flag ${ }^{+}$cells. Scale bar $=50 \mu \mathrm{m}$. TPN triple phospho-null, TPM triple phospho-mimetic. b Olig2 SUMOylation has no effect on TSM phosphorylation, but suppresses the overall serine phosphorylation of Olig2. HEK 293T cells were transfected with WT, 3KR Flag-Olig2, His-SUMO1, Myc-Ubc9, or HASenp2 as indicated. Lysates were prepared under denaturing conditions and immunoprecipitated with the anti-Flag antibody, followed by western blotting analysis using antibodies against phospho-serine (pSer), phospho-S10, S13, S14 (p-TSM) of Olig2, SUMO1, and total Olig2. c Olig2 SUMOylation is decreased by S10 phosphorylation. HEK $293 \mathrm{~T}$ cells were transfected with WT, phospho-defective or phospho-mimetic Myc-Olig2, and Flag-SUMO1 as indicated. Cell

Senp2 (Fig. 5b). However, the overall serine phosphorylation levels of Olig2 were markedly increased in $3 \mathrm{KR}$, as compared with WT Olig2-expressing cells (Figs. 5b and S3B). The phosphorylation nature of these bands was confirmed by using calf intestinal alkaline phosphatase (Fig. S3C). By contrast, the phospho-mimetic S10D and TPM exhibited markedly reduced SUMOylation, while the other forms of phospho-defective and phospho-mimetic mutants were SUMOylated similarly as the WT Olig2 (Fig. 5c). Furthermore, TSM phosphorylation was not altered in spinal cords of Senp $2^{\mathrm{f} / \mathrm{f} / \mathrm{f}}: P d g$ fra-Cre ${ }^{\mathrm{ER}}$ mice, which exhibited upregulated Olig2 SUMOylation upon TAM administration (Figs. 5d and S4). Conversely, reducing the p-TSM level with the GSK3 inhibitor, CHIR-
B

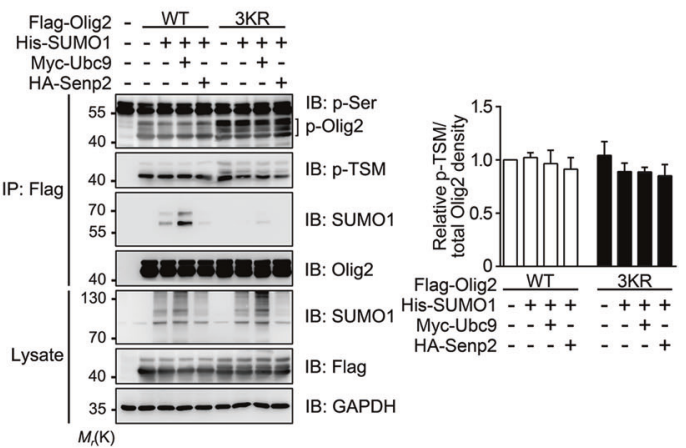

E
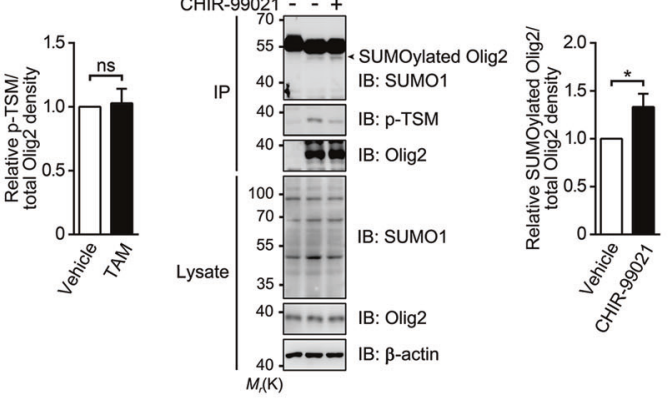

lysates were immunoprecipitated with an anti-Myc antibody and then immunoblotted with the anti-SUMO1 and anti-Olig2 antibodies. d Olig2 SUMOylation does not affect TSM phosphorylation in vivo. Mouse spinal cord tissue was dissected from Senp $2^{\mathrm{f} / \mathrm{fl}}:$ Pdgfra-Cre ${ }^{\mathrm{ER}}$ mice administrated with vehicle or tamoxifen (TAM), followed by DeIP and western blotting using anti-Olig2 and anti-p-TSM antibodies, respectively. e TSM phosphorylation suppresses Olig2 SUMOylation in vivo. Mouse spinal cord tissue was dissected from WT mice administrated with CHIR-99021 (20 mg/kg, i.p) for 5 days, followed by De-IP and western blotting using antibodies as indicated. The arrowheads indicate SUMOylated Olig2. Images shown are representatives of at least three independent experiments. Bar graphs are presented as means \pm s.e.m. of at least three independent experiments. Statistical significance was assessed by Student's $t$ test for two group comparison (d, e) or one-way ANOVA with Tukey's multiple comparison test for multiple group comparisons $(\mathbf{a}-\mathbf{c}) .{ }^{*} p<0.05$; $* * p<$ $0.01 ; * * * p<0.001 ;$ ns nonsignificant.

99021 [35], led to an increase in Olig2 SUMOylation (Fig. 5e). Taken together, our data suggest that Olig2 SUMOylation requires S10 dephosphorylation, but the SUMOylation status has no influence on TSM phosphorylation, although it decreases the overall serine phosphorylation of Olig2.

\section{Olig2 SUMOylation does not alter its stability, subcellular localization, or interaction with other proteins}

SUMOylation has been reported to alter subcellular/subnuclear distribution, stability, transcriptional activity, or protein-protein interaction of TFs [36-40]. The protein 
A

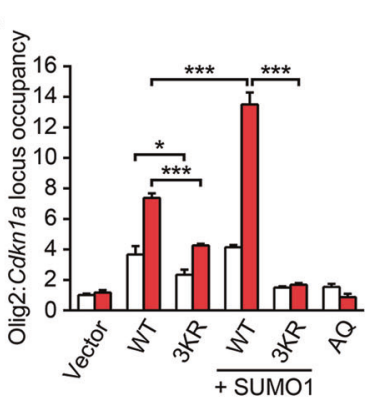

B

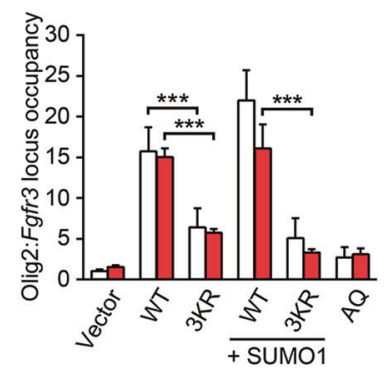

C

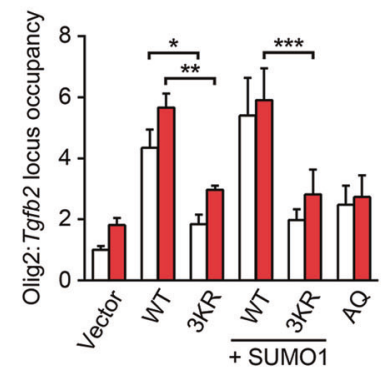

D

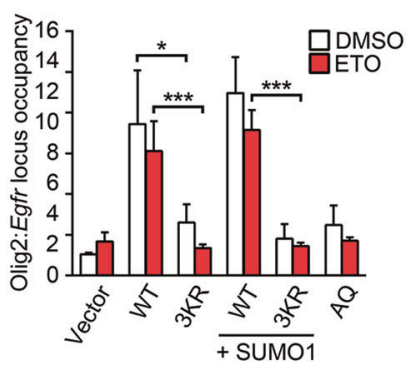

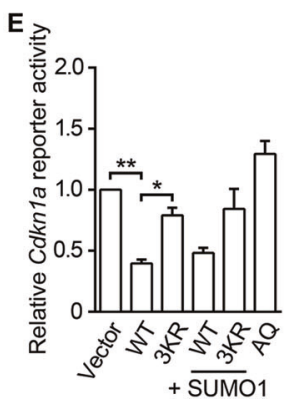

Fig. 6 Olig2 SUMOylation is required for its gene targeting. Quantitative ChIP analysis for WT or 3KR Olig2 bound to target genes Cdknla (a), Fgfr3 (b), Tgfb2 (c), and Egfr (d). Neuro-2a cells transfected with WT Flag-Olig2, 3KR Flag-Olig2, AQ Flag-Olig2, and HisSUMO1 were treated with DMSO or $20 \mu \mathrm{M}$ ETO for $24 \mathrm{~h}$ before being subject to ChIP analysis using anti-Flag antibody. The bar graphs show the ratio of fold enrichment of Olig2 at the target genes over the DMSO-treated vector control. SUMOylation-deficient Olig2 fails to repress luciferase expression driven by the $C d k n 1 a$ promoter (e) or Mycn promoter (f) in Neuro-2a cells. The luciferase activity for each group was normalized with Renilla luciferase activity. g Quantitative PCR analysis of Cdknla mRNA expression. Neuro-2a cells transfected

level of 3KR Olig2 at steady state, as well as the degradation rate, was comparable with that of WT Olig2 (Fig. S5A, B). WT and 3KR mutant displayed similar expression levels and nuclear distribution patterns, no matter treated or not with ETO (Fig. S5C, D) [12].

As a member of the bHLH family, Olig2 not only utilizes its bHLH domain to form homodimers and heterodimers with other bHLH family members, but also interacts physically with some non-bHLH TFs [41-44]. Given that one of the three SUMOylated residues, K112, is located in the bHLH domain, we examined whether SUMOylation changes the interactions of Olig2 with other proteins. Using Myc-Olig2, of which the 3KR mutant showed diminished SUMO1 conjugation (Fig. S5E) just like the Flag-tagged 3KR (Fig. S1E), we showed similar Co-IP of Flag-Olig2 by WT and 3KR Myc-Olig2 (Fig. S5F). The WT and 3KR Myc-Olig2 were also comparable at pulling down a number of Olig2-binding partners, such as Olig1, Nkx2.2, and Sox10 (Fig. S5G-I). Together, these observations indicate that the deficiency in Olig2 SUMOylation has no impact on subcellular distribution or its binding to known Olig2binding partners. with vector, WT, or 3KR Flag-Olig2 were treated with DMSO or 20 $\mu \mathrm{M}$ ETO for $36 \mathrm{~h}$, followed by RNA extraction and quantitative RTPCR analysis. The expression level of Cdknla was normalized to actin. h 3KR Olig2 is unable to recruit Hdac1. HEK 293T cells transfected with indicated plasmids (WT Flag-Olig2, 3KR Flag-Olig2, AQ Flag-Olig2, and Myc-Hdac1) were subjected to Co-IP analysis using anti-Myc antibody and then immunoblotted with anti-Olig2 antibody. Blot images are representatives of at least three independent experiments. Bar graphs are presented as means \pm s.e.m. of at least three independent experiments. Statistical significance was assessed by two-way ANOVA with Tukey's multiple comparison test for multiple group comparisons. $* p<0.05 ; * * p<0.01 ; * * *<<0.001$.

\section{Olig2 SUMOylation is required for its gene targeting}

The Cdknla gene, a well-characterized transcriptional target of both Olig2 and p53 [5], encodes a cyclin-dependent kinase 2 inhibitor that mediates p53-dependent cell cycle arrest and thereby determines the fate of tumor cells under genotoxic stress [5, 6, 45, 46]. According to ChIP assays, loss of SUMO modification significantly reduced the occupancy of ectopic Olig2 at the Cdknla locus (Fig. 6a). Although SUMO1 overexpression increased the occupancy of WT Olig2 at the Cdkn1a locus $24 \mathrm{~h}$ after ETO stimulation, it failed to affect the binding of 3KR Olig2 to this site (Fig. 6a). These suggest that SUMOylation is required for Olig2 binding to the Cdknla promoter in response to ETO treatment. As expected, the DNA-binding deficient mutant AQ (K119A/R120Q) [10] did not bind to the Cdknla locus (Fig. 6a).

Previous studies have also indicated $F g f r 3, T g f b 2$, and Egfr to be direct genetic targets of Olig2 [12]. Accordingly, we observed the binding of WT Olig2 at the Fgfr3, Tgfb2, and Egfr loci, which was significantly decreased for the $3 \mathrm{KR}$ and AQ mutants (Fig. 6b-d). To exclude the 

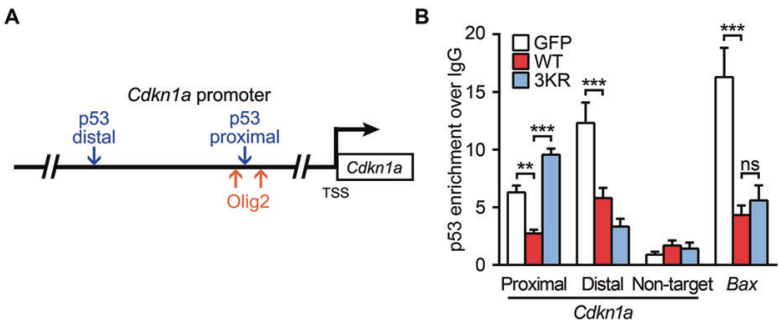

D

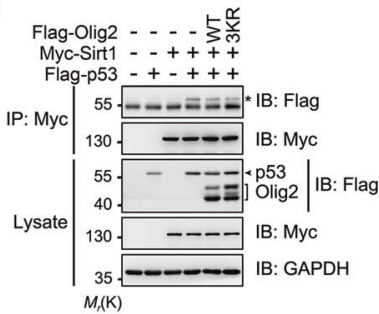

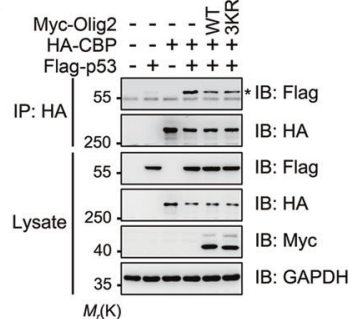

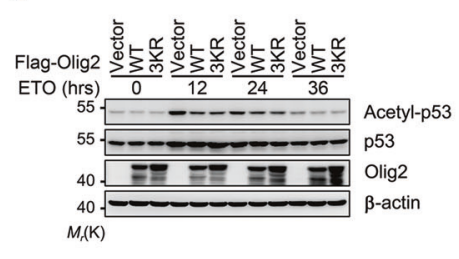

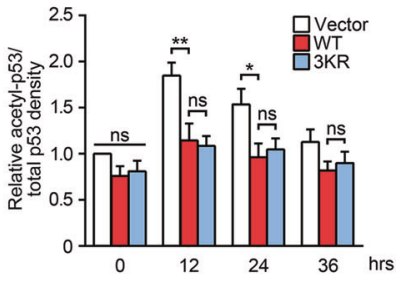

G

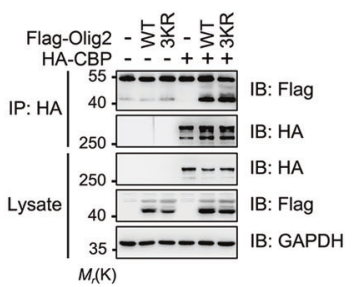

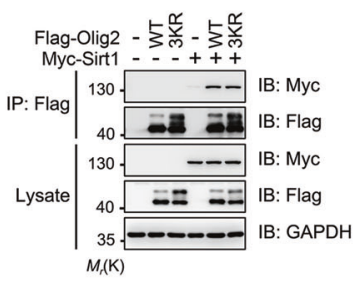

Fig. 7 Olig2 SUMOylation antagonizes p53 recruitment to Cdkn1a promoter. a Schematic showing p53 and Olig2-binding sites in Cdknla promoter region. Two p53 binding sites and two Olig2binding sites are indicated with blue and orange arrows, respectively. TSS transcription start site. b Quantitative ChIP analysis for p53 occupancy at Cdknla and Bax loci under genotoxic stress. U87-GFP, U87-Olig $2^{\mathrm{WT}}$, and U87-Olig2 ${ }^{3 \mathrm{KR}}$ cells were treated with $200 \mu \mathrm{M}$ TMZ as in Fig. 3b, but for $24 \mathrm{~h}$. Cells were then subjected to ChIP analysis using an anti-p53 antibody. The bar graph shows the ratio of fold enrichment of p53 at the target genes over $\mathrm{IgG}$ control. c Olig2 represses p53 acetylation in a SUMOylation-independent manner. Neuro-2a cells overexpressing vector, WT, or 3KR Flag-Olig2 were incubated with $20 \mu \mathrm{M}$ ETO for indicated periods. Cell lysates were subjected to western blotting with antibodies against acetylated p53 (Lys379) and total p53. d, e Olig2 inhibits the association of p53 with

possibility that the conformation change associated with the 3KR mutation, rather than Olig2 deSUMOylation, affected its DNA binding, we employed the conjugation-deficient SUMO1 G97A mutant (SUMO1 $\left.{ }^{\mathrm{GA}}\right)$. As shown in Fig. S6A-D, the DNA-binding abilities of WT Olig2 to all four DNA loci were impaired by co-expression of SUMO1 ${ }^{\mathrm{GA}}$ to similar extents as the $3 \mathrm{KR}$ mutation.

On the other hand, WT Olig2 suppressed the luciferase activities driven by Cdknla and Mycn promoters, respectively, while that of $3 \mathrm{KR}$ failed to do the same (Fig. 6e, f), consisting with the marked decrease in Cdknla transcription (Fig. $6 \mathrm{~g}$ ) and subsequently downregulation of p21 protein (Fig. S6E) in response to ETO in presence of Olig2 WT, but not 3KR. These results provide evidence that Olig2 SUMOylation is required for its transcriptional activity.

Multiple lines of evidence indicate that the nucleosome remodeling and deacetylase (NuRD) complex is recruited to the promoter region by TFs, especially oncogenic TFs, to enhance the transcriptional repression of target genes [47]. As shown in Fig. 6h, both 3KR and AQ Olig2 exhibited marked decreases in the interaction with Hdac1, a core component of NuRD complex [12], as compared with WT Olig2, demonstrating that the SUMOylation deficiency

CBP, but not with Sirt1. HEK 293T cells were transfected with WT, 3KR Flag-Olig2 (d, or Myc-Olig2 in e), Myc-Sirt1, or HA-CBP and subjected to Co-IP analysis using anti-Myc antibody (d) or anti-HA antibody (e), followed by western blotting using antibodies as indicated. f, g Olig2 SUMOylation does not affect its interaction with Sirt1 or CBP. HEK 293T cells were transfected with WT or 3KR Flag-Olig2 with Myc-Sirt1 (f) or HA-CBP (g). Cell lysates were immunoprecipitated with anti-Flag antibody (f) or anti-HA antibody (g), followed by western blotting using antibodies as indicated. The asterisks indicate co-immunoprecipitated p53. Blot images are representatives of at least three independent experiments. Bar graphs are presented as means \pm s.e.m. of at least three independent experiments. Statistical significance was assessed by one-way ANOVA with Tukey's multiple comparison test for multiple group comparisons. $* p<0.05 ; * *<0.01$; $* * * p<0.001 ;$ ns nonsignificant.

disables Olig2 to effectively recruit Hdac1 to target genes. Collectively, these results strongly support the conclusion that SUMO1 modification of Olig2 is required for transcription suppression.

\section{Olig2 SUMOylation antagonizes p53 recruitment to Cdkn1a promoter}

Deletion of p53 protects cells from genotoxic damage [6], implicating the promitogenic and antiapoptotic functions of p53. Accordingly, we confirmed the p53-dependent regulation of Olig2 in p53-null $\left(\right.$ TP53 $\left.{ }^{-/-}\right)$HCT-116 cells, in which neither $C d k n 1 a$ mRNA nor caspase-3 cleavage was induced by ETO, and hence Olig2 overexpression had no further protective effect (Fig. S7A, B). Although no convincing evidence exists for a direct interaction between Olig2 and p53 proteins [6, 12], ChIP-seq studies have shown that Olig2 binds to two promoter/enhancer elements of the Cdknla promoter region franking the proximal p53binding site (Fig. 7a) [5]. Thus, we tested the possibility that Olig2 antagonizes the recruitment of p53 to Cdknla promoter using the ChIP assay. In TMZ-treated U87-MG cells, p53 occupancy at the Cdknla promoter region 
encompassing both the proximal p53-binding site and the two franking Olig2-binding sites [5] was dramatically lower in WT Olig2-expressing cells than in cells that expressed the vector control or the $3 \mathrm{KR}$ mutant (Fig. 7b). This indicates that Olig2 binding occludes p53 recruitment to this region of the Cdknla promoter and consistent with the results shown in Fig. 6a.

Surprisingly, both WT and 3KR Olig2 significantly suppressed p53 occupancy at the distal binding site of the Cdknla promoter when compared with the vector control (Fig. 7b). Given that the expression of WT and 3KR Olig2 also similarly suppressed the binding of p53 to the Bax locus (Fig. 7b), a proapoptotic gene target of p53, but not Olig2 [5, 12, 48], this SUMOylation-independent inhibitory effect of Olig2 on p53 recruitment to its gene targets most likely represents a separate mechanism from competitive bindings between p53 and Olig2 to the same promoter region. Indeed, an early study showed that Olig2 inhibits the acetylation of p53 and consequently suppresses the cell response to genotoxic damage [6]. Accordingly, we detected comparable inhibition of ETO-induced p53 acetylation by WT and 3KR Olig2 (including 3KR-TPM) (Figs. 7c and S7C), indicating that SUMOylation is not involved in the regulation of p53 acetylation by Olig2. Acetylation of p53 catalyzed by p300/CBP, as well as deacetylation by Sirt1, are critical for p53-mediated transcriptional activation in DNA-damage response [49, 50]. Co-expression of WT and 3KR Olig2 decreased the physical associations of p53 with CBP, but not with Sirt1 (Fig. 7d, e). At the same time, the associations between Olg2 and Sirt1 and CBP, respectively, were not affected by the loss-of-SUMOylation mutation (Fig. 7f, g). Taken together, our results demonstrate that Olig2 suppresses Cdknla activation by p53 through at least two separate mechanisms: (1) a SUMOylation-dependent one that involves direct binding of Olig2 to the Cdkn1a promoter to occlude p53 binding to the proximal site and (2) a SUMOylation-independent one that inhibits p53 acetylation through disrupting p53-CBP interaction (Fig. S7D).

\section{Discussion}

Olig2, a CNS-specific TF, is well known to support tumor development. TSM-phosphorylated Olig2 enhances chemoresistance and radioresistance of human gliomas, but the precise mechanisms remain elusive $[6,11,12]$. Numerous studies have demonstrated that PTMs, such as phosphorylation, acetylation, and SUMOylation, serve as a vital link in DNA-damage response [27, 51, 52]. Here we demonstrate Olig2 as a SUMOylation target that undergoes covalent SUMO1 conjugation. Both SUMOylation and TSM-phosphorylation are required for the function of Olig2 to prevent the genotoxic-induced apoptosis. The SUMOylation of Olig2 supports its DNA-binding ability, which in turn inhibits p53-mediated gene targeting upon genotoxic damage.

\section{Crosstalk between Olig2 SUMOylation and its phosphorylation}

PTMs have emerged as important regulatory mechanisms in cellular responses to various stimuli [52, 53]. SUMOylation represents one of the most dynamic PTMs, with a diverse repertoire of effects ranging from protein localization, interaction, to transcriptional regulation [54]. In mice, TSM phosphorylation of Olig2 is essential for tumor growth and resistance to genotoxic damage $[6,11]$. Here, we show that both SUMOylation and TSM phosphorylation are important to the antiapoptotic function of Olig2 (Figs. 5a and S3A) [6]. TPM, despite the decreased SUMOylation, still exhibited the antiapoptotic function when placed in the WT (but not the 3KR) background (Figs. 5a and S3A). While the antiapoptotic effect of WT-TPM may be explained by the "SUMO Enigma," which claims that only minimal SUMOylation of a particular protein is necessary to achieve the maximal functional effects [55], the failure of WT-TPN to exert such an effect may result from the fact that Olig2 with unphosphorylated TSM binds to a transcriptionally inactive chromatin domain, making it inaccessible to target genes [12]. Thus, despite the apparent hyper-SUMOylation (Fig. 5c), WT-TPN is not expected to interact with its genetic target to elicit function.

\section{Olig2 SUMOylation in transcription repression}

SUMO modification is more often associated with transcription repression [27, 56]. Although the SUMOylation level of a particular TF (e.g., Olig2) at steady state is extremely low and hardly detectable (Fig. 1c, d), the repression effect of SUMO appears to be maximal (Fig. 6a-f) [55, 57]. A general model has been developed to accommodate these observations: SUMOylated TFs are assembled into a repression complex (e.g., the NuRD complex) in a SUMO-dependent manner. Once the complex is formed, TFs are deSUMOylated by SENPs but retained in the complex. In this case, SUMO modification initiates transcription repression, but is not required to maintain the repression [55, 57]. The recruitment of transcription repressors to SUMOylated TFs is reported to be facilitated by the SUMO interacting motifs (SIMs) located in the repressors [28, 58, 59]. In fact, a bioinformatic predictor for SUMOylation sites and SIMs, JASSA [30], identified four potential SIMs in Olig2 interacting transcription repressors Hdac1 and Mta2 [12], which are highly conserved among species. 
Given that one of the SUMO-acceptor sites K112 is located in the basic region of bHLH domain [60], SUMOylation might facilitate DNA-Olig2 interaction by being directly involved in DNA binding [61], or serving as a bridge linking basal transcriptional machinery, TFs, or coregulators and thereby recruiting Olig2 to DNA [55, 62]. We show that $3 \mathrm{KR}$ Olig2 exhibits decreased binding capacity to Hdac1, similar to the AQ mutant (Fig. 6h), but the binding to the transcription activator, CBP, is unaffected (Fig. 7g). Thus, we propose that SUMO1 covalently conjugated Olig2 interacts with DNA to form an Olig2:DNA complex that acts as a scaffold to recruit the transcription repression complex (e.g., the NuRD complex) to DNA. Interestingly, the SUMOylated Olig2 may be rapidly deconjugated by Senps, resulting in the abundant presence of non-SUMOylated Olig2 in the complex, which retains the transcription repression. Further studies are warranted to unravel the precise mechanisms on how SUMOylated Olig2 initiates transcription suppression.

\section{Olig2 SUMOylation and p53 activation}

Olig2 is expressed in multiple grades of human glioma [63-65] and is required for gliomagenesis in murine models of glioma [8]. It has been reported that Olig2 suppresses p53 gene targeting in irradiation-induced apoptosis by inhibiting acetylation of p53 [6]. Interestingly, the protective functions of Olig2 SUMOylation require E-box binding, as the DNA-binding deficient $3 \mathrm{KR}$ fails to protect cells from DNA damage (Figs. 2 and 6) [12], and repression of p53 acetylation alone is not sufficient to inhibit DNA-damage response (Figs. 2 and 7c). ChIP-seq studies have revealed a pair of E-box elements near one of the canonical p53-binding site on the Cdknla promoter [5]. Accordingly, the proximity ligation assay has indicated that Olig2 stays very close to p53 in the open chromatin, but the Olig2-p53 complex has not been successfully identified $[6,12]$. Our findings provide more detailed insights on p53 inhibition by Olig2 wherein SUMOylation promotes Olig2:Cdknla interaction that occludes p53 binding to the Cdknla promoter (Figs. 6a and $7 \mathrm{~b}$ ). In addition, Olig2 (either SUMOylated or nonSUMOylated) disrupts p53 acetylation by inhibiting the CBP-p53 interaction (Fig. 7c, e), which suppresses transactivation of other p53 target genes (e.g., Bax). Our results indicate the importance of Olig2-mediated transcription repression in DNA-damage response, which might even overwhelm its p53-acetylation suppressing function. However, a genome-wide screen for Olig 2 target genes in Olig2-null neural stem cells has identified only four Olig2-repressible genes associated with p53 signaling axis, three of which are poorly characterized [5]. Numerous DNA-damage responsible genes are upregulated or downregulated [46], wherein almost no genetic target of Olig2 has been well studied.

In summary, we demonstrate that Olig2 is SUMOylated and the SUMOylation is essential for Olig2 suppression of p53-dependent DNA-damage response. The protective effect of Olig2 SUMOylation against DNA-damage response is mediated by antagonizing p53 recruitment to the Cdknla promoter, which consequently prevents genotoxic drug-induced cell cycle arrest and apoptosis. Our work uncovers a SUMOylation-dependent regulatory mechanism of Olig2 in DNA-damage response. The more in-depth understanding of the Olig2 SUMOylation regulated pathway described here at the molecular level will facilitate the design of new strategies for treatment of tumor resistant to genotoxic stress, such as GBM.

Acknowledgements We thank Z. Kang (Lerner Research Institute, Cleveland Clinic, Cleveland, $\mathrm{OH})$ for providing Pdgfra-Cre ${ }^{\mathrm{ER}}$ mice. This work was supported by the National Natural Science Foundation of China [31830031, 31761163002, and 31671053 to YL].

\section{Compliance with ethical standards}

Conflict of interest The authors declare that they have no conflict of interest.

Publisher's note Springer Nature remains neutral with regard to jurisdictional claims in published maps and institutional affiliations.

Open Access This article is licensed under a Creative Commons Attribution 4.0 International License, which permits use, sharing, adaptation, distribution and reproduction in any medium or format, as long as you give appropriate credit to the original author(s) and the source, provide a link to the Creative Commons license, and indicate if changes were made. The images or other third party material in this article are included in the article's Creative Commons license, unless indicated otherwise in a credit line to the material. If material is not included in the article's Creative Commons license and your intended use is not permitted by statutory regulation or exceeds the permitted use, you will need to obtain permission directly from the copyright holder. To view a copy of this license, visit http://creativecommons. org/licenses/by/4.0/.

\section{References}

1. Omuro A, DeAngelis LM. Glioblastoma and other malignant gliomas: a clinical review. JAMA. 2013;310:1842-50.

2. Carro MS, Lim WK, Alvarez MJ, Bollo RJ, Zhao X, Snyder EY, et al. The transcriptional network for mesenchymal transformation of brain tumours. Nature. 2010;463:318-25.

3. Siebzehnrubl FA, Silver DJ, Tugertimur B, Deleyrolle LP, Siebzehnrubl D, Sarkisian MR, et al. The ZEB1 pathway links glioblastoma initiation, invasion and chemoresistance. EMBO Mol Med. 2013;5:1196-212.

4. Osuka S, Van Meir EG. Overcoming therapeutic resistance in glioblastoma: the way forward. J Clin Investig. 2017;127:415-26.

5. Ligon KL, Huillard E, Mehta S, Kesari S, Liu H, Alberta JA, et al. Olig2-regulated lineage-restricted pathway controls replication competence in neural stem cells and malignant glioma. Neuron. 2007;53:503-17. 
6. Mehta S, Huillard E, Kesari S, Maire CL, Golebiowski D, Harrington $\mathrm{EP}$, et al. The central nervous system-restricted transcription factor Olig2 opposes p53 responses to genotoxic damage in neural progenitors and malignant glioma. Cancer Cell. 2011;19:359-71.

7. Singh SK, Fiorelli R, Kupp R, Rajan S, Szeto E, Lo Cascio C, et al. Post-translational modifications of OLIG2 regulate glioma invasion through the TGF-beta pathway. Cell Rep. 2016;16:950-66.

8. Meijer DH, Kane MF, Mehta S, Liu H, Harrington E, Taylor CM, et al. Separated at birth? The functional and molecular divergence of OLIG1 and OLIG2. Nat Rev Neurosci. 2012;13:819-31.

9. Lu QR, Sun T, Zhu Z, Ma N, Garcia M, Stiles CD, et al. Common developmental requirement for Olig function indicates a motor neuron/oligodendrocyte connection. Cell. 2002;109:75-86.

10. Lee SK, Lee B, Ruiz EC, Pfaff SL. Olig2 and Ngn2 function in opposition to modulate gene expression in motor neuron progenitor cells. Genes Dev. 2005;19:282-94.

11. Sun Y, Meijer DH, Alberta JA, Mehta S, Kane MF, Tien AC, et al. Phosphorylation state of Olig2 regulates proliferation of neural progenitors. Neuron. 2011;69:906-17.

12. Meijer DH, Sun Y, Liu T, Kane MF, Alberta JA, Adelmant G, et al. An amino terminal phosphorylation motif regulates intranuclear compartmentalization of Olig2 in neural progenitor cells. J Neurosci. 2014;34:8507-18.

13. Bode AM, Dong Z. Post-translational modification of p53 in tumorigenesis. Nat Rev Cancer. 2004;4:793-805.

14. Flotho A, Melchior F. Sumoylation: a regulatory protein modification in health and disease. Annu Rev Biochem. 2013;82:357-85.

15. Huang J, Yan J, Zhang J, Zhu S, Wang Y, Shi T, et al. SUMO1 modification of PTEN regulates tumorigenesis by controlling its association with the plasma membrane. Nat Commun. 2012;3:911

16. Xu B, Li Q, Chen N, Zhu C, Meng Q, Ayyanathan K, et al. The LIM protein Ajuba recruits $\mathrm{DBC} 1$ and $\mathrm{CBP} / \mathrm{p} 300$ to acetylate ERalpha and enhances ERalpha target gene expression in breast cancer cells. Nucleic Acids Res. 2019;47:2322-35.

17. Lutz W, Schwab M. In vivo regulation of single copy and amplified $\mathrm{N}$-myc in human neuroblastoma cells. Oncogene. 1997;15:303-15

18. Gartel AL, Ye X, Goufman E, Shianov P, Hay N, Najmabadi F, et al. Myc represses the $\mathrm{p} 21$ (WAF1/CIP1) promoter and interacts with Sp1/Sp3. Proc Natl Acad Sci USA. 2001;98:4510-5.

19. Wang Y, Wang Y, Zhang H, Gao Y, Huang C, Zhou A, et al. Sequential posttranslational modifications regulate PKC degradation. Mol Biol Cell. 2016;27:410-20.

20. Sun H, Lu L, Zuo Y, Wang Y, Jiao Y, Zeng WZ, et al. Kainate receptor activation induces glycine receptor endocytosis through PKC deSUMOylation. Nat Commun. 2014;5:4980.

21. Griveau A, Seano G, Shelton SJ, Kupp R, Jahangiri A, Obernier $\mathrm{K}$, et al. A glial signature and Wnt7 signaling regulate gliomavascular interactions and tumor microenvironment. Cancer Cell. 2018;33:874-89 e7.

22. Park JH, Lee SW, Yang SW, Yoo HM, Park JM, Seong MW, et al. Modification of DBC1 by SUMO2/3 is crucial for p53mediated apoptosis in response to DNA damage. Nat Commun. 2014;5:5483.

23. Sun C, Qiao H, Zhou Q, Wang Y, Wu Y, Zhou Y, et al. Modulation of GluK2a subunit-containing kainate receptors by 14-3-3 proteins. J Biol Chem. 2013;288:24676-90.

24. Franken NA, Rodermond HM, Stap J, Haveman J, van Bree C. Clonogenic assay of cells in vitro. Nat Protoc. 2006;1:2315-9.

25. Camphausen K, Purow B, Sproull M, Scott T, Ozawa T, Deen DF, et al. Influence of in vivo growth on human glioma cell line gene expression: convergent profiles under orthotopic conditions. Proc Natl Acad Sci USA. 2005;102:8287-92.

26. Verger A, Perdomo J, Crossley M. Modification with SUMO. A role in transcriptional regulation. EMBO Rep. 2003;4:137-42.

27. Seeler JS, Dejean A. SUMO and the robustness of cancer. Nat Rev Cancer. 2017;17:184-97.

28. Henley JM, Craig TJ, Wilkinson KA. Neuronal SUMOylation: mechanisms, physiology, and roles in neuronal dysfunction. Physiol Rev. 2014;94:1249-85.

29. Zhao Q, Xie Y, Zheng Y, Jiang S, Liu W, Mu W, et al. GPSSUMO: a tool for the prediction of sumoylation sites and SUMOinteraction motifs. Nucleic Acids Res. 2014;42:W325-30.

30. Beauclair G, Bridier-Nahmias A, Zagury JF, Saib A, Zamborlini A. JASSA: a comprehensive tool for prediction of SUMOylation sites and SIMs. Bioinformatics. 2015;31:3483-91.

31. Blomster HA, Imanishi SY, Siimes J, Kastu J, Morrice NA, Eriksson JE, et al. In vivo identification of sumoylation sites by a signature tag and cysteine-targeted affinity purification. J Biol Chem. 2010;285:19324-9.

32. Knuesel M, Cheung HT, Hamady M, Barthel KK, Liu X. A method of mapping protein sumoylation sites by mass spectrometry using a modified small ubiquitin-like modifier 1 (SUMO-1) and a computational program. Mol Cell Proteom. 2005;4:1626-36.

33. Pommier Y, Leo E, Zhang H, Marchand C. DNA topoisomerases and their poisoning by anticancer and antibacterial drugs. Chem Biol. 2010;17:421-33.

34. Leroy B, Girard L, Hollestelle A, Minna JD, Gazdar AF, Soussi T. Analysis of TP53 mutation status in human cancer cell lines: a reassessment. Hum Mutat. 2014;35:756-65.

35. Zhou J, Tien AC, Alberta JA, Ficarro SB, Griveau A, Sun Y, et al. A sequentially priming phosphorylation cascade activates the gliomagenic transcription factor Olig2. Cell Rep. 2017;18:3167-77.

36. Carter S, Bischof O, Dejean A, Vousden KH. C-terminal modifications regulate MDM2 dissociation and nuclear export of $\mathrm{p} 53$. Nat Cell Biol. 2007;9:428-35.

37. Wei F, Scholer HR, Atchison ML. Sumoylation of Oct4 enhances its stability, DNA binding, and transactivation. J Biol Chem. 2007;282:21551-60.

38. Lee HY, Johnson KD, Fujiwara T, Boyer ME, Kim SI, Bresnick $\mathrm{EH}$. Controlling hematopoiesis through sumoylation-dependent regulation of a GATA factor. Mol Cell. 2009;36:984-95.

39. Wu SY, Chiang CM. Crosstalk between sumoylation and acetylation regulates p53-dependent chromatin transcription and DNA binding. EMBO J. 2009;28:1246-59.

40. Sun XX, Chen Y, Su Y, Wang X, Chauhan KM, Liang J, et al. SUMO protease SENP1 deSUMOylates and stabilizes c-Myc. Proc Natl Acad Sci USA. 2018;115:10983-8.

41. Sun $\mathrm{T}$, Dong $\mathrm{H}, \mathrm{Wu} \mathrm{L}$, Kane $\mathrm{M}$, Rowitch $\mathrm{DH}$, Stiles $\mathrm{CD}$. Cross-repressive interaction of the Olig2 and $\mathrm{Nkx} 2.2$ transcription factors in developing neural tube associated with formation of a specific physical complex. J Neurosci. 2003;23: 9547-56.

42. Wang SZ, Dulin J, Wu H, Hurlock E, Lee SE, Jansson K, et al. An oligodendrocyte-specific zinc-finger transcription regulator cooperates with Olig2 to promote oligodendrocyte differentiation. Development. 2006;133:3389-98.

43. Wissmuller S, Kosian T, Wolf M, Finzsch M, Wegner M. The high-mobility-group domain of Sox proteins interacts with DNAbinding domains of many transcription factors. Nucleic Acids Res. 2006;34:1735-44.

44. Li H, Lu Y, Smith HK, Richardson WD. Olig1 and Sox10 interact synergistically to drive myelin basic protein transcription in oligodendrocytes. J Neurosci. 2007;27:14375-82. 
45. Adams PD, Kaelin WG Jr. Negative control elements of the cell cycle in human tumors. Curr Opin Cell Biol. 1998;10:791-7.

46. Roos WP, Thomas AD, Kaina B. DNA damage and the balance between survival and death in cancer biology. Nat Rev Cancer. 2016;16:20-33.

47. Lai AY, Wade PA. Cancer biology and NuRD: a multifaceted chromatin remodelling complex. Nat Rev Cancer. 2011;11:588-96.

48. Mateo JL, van den Berg DL, Haeussler M, Drechsel D, Gaber ZB, Castro DS, et al. Characterization of the neural stem cell gene regulatory network identifies OLIG2 as a multifunctional regulator of self-renewal. Genome Res. 2015;25:41-56.

49. Tang Y, Zhao W, Chen Y, Zhao Y, Gu W. Acetylation is indispensable for p53 activation. Cell. 2008;133:612-26.

50. Vaziri H, Dessain SK, Eaton EN, Imai S-I, Frye RA, Pandita TK, et al. hSIR2SIRT1 functions as an NAD-dependent p53 deacetylase. Cell. 2001;107:149-59.

51. Huen MS, Chen J. The DNA damage response pathways: at the crossroad of protein modifications. Cell Res. 2008;18:8-16.

52. Dantuma NP, van Attikum H. Spatiotemporal regulation of posttranslational modifications in the DNA damage response. EMBO J. 2016;35:6-23.

53. Eifler K, Vertegaal ACO. SUMOylation-mediated regulation of cell cycle progression and cancer. Trends Biochem Sci. 2015;40:779-93.

54. Gareau JR, Lima CD. The SUMO pathway: emerging mechanisms that shape specificity, conjugation and recognition. Nat Rev Mol Cell Biol. 2010;11:861-71.

55. Hay RT. SUMO: a history of modification. Mol Cell. 2005;18:1-12.
56. Cubenas-Potts C, Matunis MJ. SUMO: a multifaceted modifier of chromatin structure and function. Dev Cell. 2013;24:1-12.

57. Johnson ES. Protein modification by SUMO. Annu Rev Biochem. 2004;73:355-82.

58. Chang CC, Lin DY, Fang HI, Chen RH, Shih HM. Daxx mediates the small ubiquitin-like modifier-dependent transcriptional repression of Smad4. J Biol Chem. 2005;280:10164-73.

59. Lin DY, Huang YS, Jeng JC, Kuo HY, Chang CC, Chao TT, et al. Role of SUMO-interacting motif in Daxx SUMO modification, subnuclear localization, and repression of sumoylated transcription factors. Mol Cell. 2006;24:341-54.

60. Ellenberger T, Fass D, Arnaud M, Harrison SC. Crystal structure of transcription factor E47: E-box recognition by a basic region helix-loop-helix dimer. Genes Dev. 1994;8:970-80.

61. Eilebrecht S, Smet-Nocca C, Wieruszeski JM, Benecke A. SUMO-1 possesses DNA binding activity. BMC Res Notes. 2010;3:146.

62. Ulrich HD. Two-way communications between ubiquitin-like modifiers and DNA. Nat Struct Mol Biol. 2014;21:317-24.

63. Lu QR, Park JK, Noll E, Chan JA, Alberta J, Yuk D, et al. Oligodendrocyte lineage genes (OLIG) as molecular markers for human glial brain tumors. Proc Natl Acad Sci USA. 2001;98:10851-6.

64. Marie Y, Sanson M, Mokhtari K, Leuraud P, Kujas M, Delattre JY, et al. OLIG2 as a specific marker of oligodendroglial tumour cells. Lancet. 2001;358:298-300.

65. Ligon KL, Alberta JA, Kho AT, Weiss J, Kwaan MR, Nutt CL, et al. The oligodendroglial lineage marker OLIG2 is universally expressed in diffuse gliomas. J Neuropathol Exp Neurol. 2004;63:499-509. 